\title{
Comparison of HDO measurements from Envisat/MIPAS with observations by Odin/SMR and SCISAT/ACE-FTS
}

\author{
S. Lossow ${ }^{1}$, J. Steinwagner ${ }^{2}$, J. Urban ${ }^{3}$, E. Dupuy ${ }^{4}$, C. D. Boone ${ }^{5}$, S. Kellmann ${ }^{1}$, A. Linden ${ }^{1}$, M. Kiefer ${ }^{1}$, \\ U. Grabowski ${ }^{1}$, N. Glatthor ${ }^{1}$, M. Höpfner ${ }^{1}$, T. Röckmann ${ }^{2}$, D. P. Murtagh ${ }^{3}$, K. A. Walker ${ }^{6}$, P. F. Bernath ${ }^{7}$, \\ T. von Clarmann ${ }^{1}$, and G. P. Stiller ${ }^{1}$ \\ ${ }^{1}$ Karlsruhe Institute of Technology, Institute for Meteorology and Climate Research, Hermann-von-Helmholtz-Platz 1, \\ 76344 Leopoldshafen, Germany \\ ${ }^{2}$ Utrecht University, Institute for Marine and Atmospheric Research Utrecht, Princetonplein 5, \\ 3584 CC Utrecht, The Netherlands \\ ${ }^{3}$ Chalmers University of Technology, Department of Earth and Space Sciences, Hörsalsvägen 11, 41296 Göteborg, Sweden \\ ${ }^{4}$ National Institute of Information and Communications Technology (NICT), Applied Electromagnetic Research Center, \\ 4-2-1 Nukui-kita, Koganei, Tokyo, 184-8795, Japan \\ ${ }^{5}$ University of Waterloo, Department of Chemistry, 200 University Avenue West, Waterloo, Ontario, N2L 3G1, Canada \\ ${ }^{6}$ University of Toronto, Department of Physics, 60 St. George Street, Toronto, Ontario, M5S 1A7, Canada \\ ${ }^{7}$ University of York, Department of Chemistry, Heslington, York, YO10 5DD, UK
}

Received: 11 February 2011 - Published in Atmos. Meas. Tech. Discuss.: 11 March 2011

Revised: 28 June 2011 - Accepted: 5 September 2011 - Published: 13 September 2011

\begin{abstract}
Measurements of thermal emission in the midinfrared by Envisat/MIPAS allow the retrieval of HDO information roughly in the altitude range between $10 \mathrm{~km}$ and $50 \mathrm{~km}$. From June 2002 to March 2004 MIPAS performed measurements in the full spectral resolution mode. To assess the quality of the HDO data set obtained during that period comparisons with measurements by Odin/SMR and SCISAT/ACE-FTS were performed. Comparisons were made on profile-to-profile basis as well as using seasonal and monthly averages. All in all the comparisons yield favourable results. The largest deviations between MIPAS and ACE-FTS are observed below $15 \mathrm{~km}$, where relative deviations can occasionally exceed $100 \%$. Despite these deviations in the absolute amount of HDO the latitudinal structures observed by both instruments are consistent in this altitude range. Between $15 \mathrm{~km}$ and $20 \mathrm{~km}$ there is less good agreement, in particular in the Antarctic during winter and spring. Also in the tropics some deviations are found. Above $20 \mathrm{~km}$ there is a high consistency in the structures observed by all three instruments. MIPAS and ACE-FTS typically agree
\end{abstract}

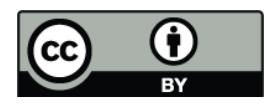

Correspondence to: S. Lossow (stefan.lossow@kit.edu) within $10 \%$, with MIPAS mostly showing higher abundances than ACE-FTS. Both data sets show considerably more HDO than SMR. This bias can be explained basically by uncertainties in spectroscopic parameters. Above $40 \mathrm{~km}$, where the MIPAS HDO retrieval reaches its limits, still good agreement with the structures observed by SMR is found for most seasons. This puts some confidence in the MIPAS data at these altitudes.

\section{Introduction}

Water vapour is one of the fundamental constituents of the Earth's atmosphere. As the most important greenhouse gas in the troposphere and lower stratosphere any long-term change of its abundance in this altitude region will inevitably have important implications for the climate on Earth. But even changes in water vapour at higher stratospheric altitudes can significantly influence the surface climate (Forster and Shine, 1999; Solomon et al., 2010). Water vapour is also a main constituent of polar stratospheric clouds (PSCs). The heterogeneous chemistry that takes place on the cloud particle surfaces plays a decisive role for the severe ozone depletion that can be observed in the polar lower stratosphere during

Published by Copernicus Publications on behalf of the European Geosciences Union. 
winter and spring time. At the same time water vapour is also the primary source of hydrogen radicals $\left(\mathrm{HO}_{\mathrm{x}}=\mathrm{OH}, \mathrm{H}\right.$, $\mathrm{HO}_{2}$ ) in the middle atmosphere. These radicals participate in the auto-catalytic cycles that destroy ozone with their contribution dominating above $50 \mathrm{~km}$ (Brasseur and Solomon, 2005).

Most water vapour resides in the troposphere. With increasing altitude the abundance of water vapour typically decrease in the troposphere as the decreasing temperatures reduce the water vapour saturation pressure. The entry of water vapour into the stratosphere occurs primarily through the cold tropical tropopause layer (TTL) where a large fraction of water vapour is removed due to freeze-drying. A large range of temporal and spatial scales are assumed to be of importance, still final consensus on the exact mechanisms and path ways behind the dehydration in the tropical tropopause region has not been reached. A secondary pathway of water vapour into the stratosphere is along isentropic surfaces that span both the uppermost troposphere and lowermost stratosphere (Holton et al., 1995). Overall the mean input of water vapour into the stratosphere amounts to about 3.5 ppmv-4.0 ppmv (e.g. Kley et al., 2000). In the stratosphere water vapour is produced by the irreversible oxidation of methane. This oxidation continues in the mesosphere but above $60 \mathrm{~km}$ this process stops to contribute significantly to the overall water vapour budget. An additional minor source in the upper stratosphere is the oxidation of molecular hydrogen (Wrotny et al., 2010). The main sink of water vapour in the stratosphere is the reaction with $\mathrm{O}\left({ }^{1} \mathrm{D}\right)$. Of small importance are dehydration effects by the sedimentation of PSCs particles in the polar vortices (Kelly et al., 1989; Vömel et al., 1995). The interaction of the altitude-dependent water vapour production, destruction and transport processes leads to an increase of water vapour with altitude in the stratosphere. A local water vapour maximum is typically found around the stratopause, indicating an equilibrium between all processes. In the mesosphere no major water vapour source exists in general. Hence, the water vapour budget in this atmospheric layer is dominated by destruction processes, primarily photodissociation, resulting in a steady decrease of the water vapour abundance with increasing altitude.

The present work focuses on monodeuterated water vapour $\left(\mathrm{HD}^{16} \mathrm{O}\right.$, hereafter $\left.\mathrm{HDO}\right)$ in the stratosphere. Like the other minor water vapour isotopologues (e.g. $\mathrm{H}_{2}^{17} \mathrm{O}, \mathrm{H}_{2}^{18} \mathrm{O}$, $\mathrm{HT}^{16} \mathrm{O}, \mathrm{HD}^{17} \mathrm{O}, \mathrm{D}_{2}^{16} \mathrm{O}, \mathrm{HD}^{18} \mathrm{O}, \mathrm{D}_{2}^{17} \mathrm{O}, \mathrm{T}_{2}^{16} \mathrm{O}, \mathrm{D}_{2}^{18} \mathrm{O}, \ldots$, sorted by molar mass) HDO is several orders of magnitude less abundant than the main isotope $\mathrm{H}_{2}^{16} \mathrm{O}$ (hereafter $\mathrm{H}_{2} \mathrm{O}$ ). HDO can be used as a tracer of dynamical processes in the middle atmosphere, however the main interest lies in the ratio of HDO with other isotopologues, typically with $\mathrm{H}_{2} \mathrm{O}$. This ratio can eventually provide more information than a single isotope alone. The standard convention to express the isotopic ratio between $\mathrm{HDO}$ and $\mathrm{H}_{2} \mathrm{O}$ is the $\delta \mathrm{D}$ notation: $\delta \mathrm{D}=\left(\frac{R_{\text {sample }}}{R_{\text {reference }}}-1\right) \cdot 1000 \%$.

$\delta \mathrm{D}$ actually describes the relative deviation of the deuterium [D] to hydrogen $[\mathrm{H}]$ ratio $R=[\mathrm{D}] /[\mathrm{H}]$ in a sample with respect to the reference ratio $R_{\text {reference }}$, which has been designated by the International Atomic Energy Agency in 1968 as $R_{\text {reference }}=155.76 \times 10^{-6}=$ VSMOW (Vienna Standard Mean Ocean Water, Hagemann et al., 1970). For the application of $\mathrm{HDO}$ and $\mathrm{H} 2 \mathrm{O}$ in the $\delta \mathrm{D}$ framework the following relation needs to be taken into account, where $i$ denotes the individual oxygen isotopologues:

$$
\begin{aligned}
R_{\text {sample }} & =\left(\frac{[\mathrm{D}]}{[\mathrm{H}]}\right)_{\text {sample }} \\
& =\left(\frac{\sum_{i=16}^{18}\left[\mathrm{HD}^{i} \mathrm{O}\right]+2 \cdot \sum_{i=16}^{18}\left[\mathrm{D}_{2}^{i} \mathrm{O}\right]}{2 \cdot \sum_{i=16}^{18}\left[\mathrm{H}_{2}^{i} \mathrm{O}\right]+\sum_{i=16}^{18}\left[\mathrm{HD}^{i} \mathrm{O}\right]}\right)_{\text {sample }} \\
& \approx\left(\frac{\left[\mathrm{HD}^{16} \mathrm{O}\right]}{2 \cdot\left[\mathrm{H}_{2}^{16} \mathrm{O}\right]}\right)_{\text {sample }} \equiv\left(\frac{[\mathrm{HDO}]}{2 \cdot\left[\mathrm{H}_{2} \mathrm{O}\right]}\right)_{\text {sample }}
\end{aligned}
$$

The approximation considers that [D] is almost entirely determined by the fraction of deuterium in $\mathrm{HD}^{16} \mathrm{O}$ while the contributions from the other isotopologues are negligible. Likewise the fraction of hydrogen in $\mathrm{H}_{2}^{16} \mathrm{O}$ completely dominates the $[\mathrm{H}]$ budget. A water vapour sample with $50 \%$ of its HDO removed would for example yield an isotopic ratio $\delta \mathrm{D}$ of $-500 \%$, if all $\mathrm{HDO}$ is removed then $\delta \mathrm{D}$ is $-1000 \%$. The dominating effect in the atmosphere influencing the $[\mathrm{D}] /[\mathrm{H}]$ ratio is the vapour pressure isotope effect. As HDO is heavier than $\mathrm{H}_{2} \mathrm{O}$ it has a lower vapour pressure leading to a change in the isotopic ratio whenever a phase change occurs. For this reason the isotopic composition has been suggested as a valuable tool in determining the entry processes and pathways of water vapour into the stratosphere (Moyer et al., 1996). This has stimulated numerous observational and model studies primarily aiming at the resolution of the long-standing debate on the relative importance of gradual ascent and convective processes to the stratospheric input of water vapour (e.g. Johnson et al., 2001b; Webster and Heymsfield, 2003; Kuang et al., 2003; Gettelman and Webster, 2005; Payne et al., 2007; Nassar et al., 2007; Hanisco et al., 2007; Steinwagner et al., 2010; Notholt et al., 2010; Sayres et al., 2010). Measurements place the typical stratospheric entry value of $\delta \mathrm{D}$ in the range between $-500 \%$ and $-700 \%$. These values deviate from what is expected from the freeze-drying of air masses by gradual ascent (so-called Rayleigh fractionation), which would lead to $\delta \mathrm{D}$ values of about $-900 \%$ near the tropopause. The enrichment relative to this value clearly indicates that other processes, like mixing of air masses, fast convective processes that do not obey Rayleigh fractionation, or lofting and re-evaporation of isotopically enriched ice crystals, must play a role. The isotopic ratio between $\mathrm{HDO}$ and $\mathrm{H}_{2} \mathrm{O}$ has not only scientific relevance 
for the troposphere-stratosphere exchange but also in regions where polar stratospheric clouds occur. The limited number of observations as well as model efforts exhibit a significant influence of these clouds on the $\delta \mathrm{D}$ distribution (Stowasser et al., 1999; Ridal, 2001; Payne et al., 2007).

Air-borne measurements on campaign basis throughout 1978 and 2005 have indicated a decrease of $\delta \mathrm{D}$ in the air column above $13 \mathrm{~km}$ in the northern hemisphere (Coffey et al., 2006). This decrease is the result of a decrease in HDO and an increase in $\mathrm{H}_{2} \mathrm{O}$ over this time period. The latter trend is consistent with other observations that show this temporal behaviour until about 2000 (Oltmans et al., 2000; Rosenlof et al., 2001; Scherer et al., 2008; Hurst et al., 2011). The trend in HDO remains unexplained even to date. Based on balloon-borne observations of water vapour isotopologues a recent investigation concluded that the stratospheric trend of $\mathrm{H}_{2} \mathrm{O}$ cannot be explained by an increase of the $\mathrm{H}_{2} \mathrm{O}$ throughput from the tropical troposphere to the stratosphere (Notholt et al., 2010).

The low abundance of HDO has made its observation difficult and consequently the existing data base is limited. First observations of HDO in the altitude range of interest date back to the late 1960s and 1970s employing a direct sampling technique (Scholz et al., 1970; Pollock et al., 1980). Over the years a number of balloon- and air-borne observations were performed, both in-situ and by means of remote sensing (e.g. Rinsland et al., 1984; Abbas et al., 1987; Dinelli et al., 1991; Zahn et al., 1998; Stowasser et al., 1999; Johnson et al., 2001a; Webster and Heymsfield, 2003; Coffey et al., 2006; Hanisco et al., 2007; Sayres et al., 2010). These observations were generally made on a campaign basis covering limited spatial and temporal scales. The first space-borne observations were made by the ATMOS (Atmospheric Trace Molecule Spectroscopy, Farmer, 1987) Fourier transform spectrometer that was carried by the Space Shuttle during four missions (April/May 1985, April 1992, April 1993 and November 1994, Rinsland et al., 1991; Irion et al., 1996; Moyer et al., 1996; Kuang et al., 2003). From August 1996 to June 1997 the IMG (Interferometric Monitor for Greenhouse gases, Kobayashi et al., 1999) instrument on board ADEOS (Advanced Earth Observing Satellite) provided observations of HDO in the troposphere and the lowermost stratosphere in the extra-tropics using the nadir sounding technique. Since the new millennium the observations by Odin/SMR (Sub-Millimetre Radiometer, Murtagh et al., 2002), Envisat/MIPAS (Michelson Interferometer for Passive Atmospheric Sounding, Fischer et al., 2008) and SCISAT/ACE-FTS (Atmospheric Chemistry Experiment - Fourier Transform Spectrometer, Bernath et al., 2005) form the backbone of the HDO observations and other minor water vapour isotopologues in the stratosphere. In February 2001 the Swedish-led Odin satellite was launched. One year later the European Envisat (Environmental Satellite) started its operations, followed by the Canadian SCISAT (Science Satellite, also known as ACE mission) satellite in
2003. In the troposphere HDO data are currently available from observations by Envisat/SCIAMACHY (Scanning Imaging Absorption Spectrometer for Atmospheric Chartography, Bovensmann et al., 1999), Aura/TES (Tropospheric Emission Spectrometer, Beer et al., 2001) and the IASI (Infrared Atmospheric Sounding Interferometer, Clerbaux et al., 2007) instruments aboard the MetOp series of polar orbiting meteorological satellites operated by EUMESAT (European Organisation for the Exploitation of Meteorological Satellites) (Worden et al., 2007; Frankenberg et al., 2009; Herbin et al., 2009). Alongside with these new satellite observations also model simulations of water vapour isotopologues gained importance (e.g. Ridal, 2001; Gettelman and Webster, 2005; Schmidt et al., 2005; Zahn et al., 2006; Risi et al., 2008).

In this paper we present contemporary comparisons of Envisat/MIPAS HDO measurements with observations by Odin/SMR and SCISAT/ACE-FTS in order to assess the quality of the satellite data sets in the stratosphere. In the next section the MIPAS data set and its characteristics are described. This includes a short overview of the mean annual distribution of HDO for different latitude bands. In Sect. 3 the Odin/SMR and SCISAT/ACE-FTS data sets are described and subsequently the comparison approach and results are presented. The outcome of the comparisons is discussed in Sect. 4.

\section{Envisat/MIPAS observations of HDO}

Carried by an Ariane-5 rocket Envisat was launched into a polar, sun-synchronous orbit on 1 March 2002 from the Guyana Space Centre in Kourou (French Guyana). The satellite orbits the Earth at an altitude of about $790 \mathrm{~km} 14$ times a day, passing the equator shortly after 10:00 LT on the descending node. On the ascending node the equator crossing time is around 22:00 LT. The satellite carries 10 instruments observing the Earth and its atmosphere for investigations of a wide scientific spectrum. The MIPAS instrument is a cooled high-resolution Fourier transform spectrometer measuring thermal emission at the atmospheric limb. The instrument operates in five spectral bands in the range between $685 \mathrm{~cm}^{-1}$ and $2410 \mathrm{~cm}^{-1}(4.1-14.6 \mu \mathrm{m})$ and uses a rearward viewing direction (Fischer et al., 2008).

\subsection{Data set}

In this comparison we focus on the MIPAS observations that were performed with full spectral resolution, that is $0.035 \mathrm{~cm}^{-1}$ (unapodised). These observations cover the time period between June 2002 to March 2004. After this date only measurements with a spectral resolution of $0.0625 \mathrm{~cm}^{-1}$ were possible, due to problems with the movement of the interferometer reflectors. The measurements of interest here were performed in the "nominal observation mode" which comprises scans at the atmospheric limb between $6 \mathrm{~km}$ and 
$68 \mathrm{~km}$. In this mode spectra at in total 17 tangent heights are taken $(6 \mathrm{~km}$ to $42 \mathrm{~km}$ in $3 \mathrm{~km}$ steps, $42 \mathrm{~km}$ to $52 \mathrm{~km}$ in $5 \mathrm{~km}$ steps and $52 \mathrm{~km}$ to $68 \mathrm{~km}$ in $8 \mathrm{~km}$ steps). A whole scan takes $76 \mathrm{~s}$ corresponding to a horizontal sampling of roughly one scan per $500 \mathrm{~km}$ assuming a satellite velocity of about $7 \mathrm{~km} \mathrm{~s}^{-1}$, when projected on the ground. The instantaneous field of view (FOV) of the MIPAS instrument is $3 \mathrm{~km}$ in the vertical and $30 \mathrm{~km}$ in the horizontal, i.e. perpendicular to the line of sight. While the latitudinal coverage of the Envisat orbit does not reach entirely to the poles, the MIPAS pointing system employs an azimuth mirror that is tilted off the orbital track to allow also measurements at the highest latitudes.

The HDO data set that is utilised in this study has been retrieved with the IMK/IAA processor, which is a joint effort by the "Institut für Meteorologie und Klimaforschung" (IMK) in Karlsruhe (Germany) and the "Instituto de Astrofísica de Andalucía" (IAA) in Granada (Spain). HDO information is retrieved from 14 microwindows in the spectral range between $1250 \mathrm{~cm}^{-1}$ and $1483 \mathrm{~cm}^{-1}(6.7-8 \mu \mathrm{m})$. The retrieval employs a non-linear least square approach (von Clarmann et al., 2003) with a first-order Tikhonov-type regularisation (Tikhonov, 1963a,b; Tikhonov and Arsenin, 1977) to avoid unphysical oscillations in the derived profiles. The radiative transfer through the atmosphere is modelled by the KOPRA (Karlsruhe Optimized and Precise Radiative Transfer Algorithm) model (Stiller, 2000). Spectroscopic data is taken from a special compilation by Flaud et al. (2003), which is largely based on parameter from the HITRAN (High Resolution Transmission, Rothman et al., 2003) and GEISA (Gestion et Etude des Informations Spectroscopiques Atmosphériques, Jacquinet-Husson et al., 1999) spectroscopy databases that were available at the time. For the minor water vapour isotopologues the spectroscopic parameter are equal to the updated version of HITRAN-2000 (Rothman et al., 2003). Vertical profiles of HDO can be retrieved roughly in the altitude range from $10 \mathrm{~km}$ to $50 \mathrm{~km}$. At the lower altitude end the opaqueness of the atmosphere determined by cloudiness, aerosols and increasing water vapour absorption limits the retrieval of HDO information. The upper limit is set by the signal-to-noise ratio. Up to an altitude of $40 \mathrm{~km}$ the vertical resolution of the retrieved data is around 5-6 km and the random noise error of a single profile amounts to about $20 \%$ (Steinwagner et al., 2007). Above $40 \mathrm{~km}$ the vertical resolution degrades as a combined consequence of the coarser measurement grid and the aforementioned decrease in the signalto-noise ratio. The random noise error deteriorates as well and therefore data averaging above $45 \mathrm{~km}$ is recommended in order to get significant results. A more detailed description of the IMK/IAA retrieval of monodeuterated water vapour can be found in Steinwagner et al. (2007). In this comparison we utilise data derived with the latest HDO retrieval version V3O_HDO_5. Overall the utilised MIPAS HDO dataset comprises more than 465000 individual profiles with almost daily coverage.

\subsection{Distribution overview}

As the number of global HDO data sets in the stratosphere is very limited the following subsection is dedicated to provide an introductory overview of the HDO distribution as observed by Envisat/MIPAS. Here the focus is on the annual cycle of HDO. Latitudinal cross sections will be shown later in the seasonal comparisons presented in Sect. 3.3. The individual panels of Fig. 1 show the mean annual cycle for various latitude bands based on the MIPAS observations with full spectral resolution between June 2002 and March 2004. Please note that the time axis of the panels representing the mid- and polar latitudes has been adjusted in phase such that the summer season occurs always in the middle of these panels. The annual cycle was calculated as a 30-day running average, always centred at the first and mid day of the individual months. Hence, two adjacent data points in the time domain are not completely independent from each other. An average is based on at least 25 individual measurements. Where this requirement was not fulfilled the average was discarded (white areas).

As evident from the panels in the two uppermost rows of Fig. 1 the "tape recorder" effect (Mote et al., 1996) dominates the annual variation of HDO in the lower stratosphere in the tropical region (Steinwagner et al., 2010). At an altitude of $18 \mathrm{~km}$ in the latitude band from $5^{\circ} \mathrm{S}-5^{\circ} \mathrm{N}$ the MIPAS measurements show the lowest abundances during the boreal spring while the annual maximum can be observed in boreal autumn. From there the "tape recorder" signal is transported upwards by about $8 \mathrm{~km}$ to $10 \mathrm{~km}$ per year. Higher up in the upper stratosphere clear signatures of the semi-annual oscillation can be observed in HDO. Maximum abundances can be observed after the solstices, consistent with earlier observations of this feature in $\mathrm{H}_{2} \mathrm{O}$ (Randel et al., 1998). The annual cycle in the mid-latitudes and polar region of stratospheric HDO is dominated by an annual component controlled by the annual cycle in the mean meridional circulation patterns. In the polar stratosphere a displacement of the vertical HDO maximum from the stratopause towards lower altitudes can be observed during winter due to the subsidence inside the polar vortex. Higher up in the upper stratosphere the annual HDO maximum can be found after the summer season as known from $\mathrm{H}_{2} \mathrm{O}$ measurements (Seele and Hartogh, 1999).

\section{Comparison}

The quality assessment of the MIPAS data set of monodeuterated water vapour primarily focuses on the stratosphere. The comparison of the MIPAS HDO data set with the Odin/SMR and SCISAT/ACE-FTS results relies basically on two approaches. The first approach uses profile-to-profile comparison on the basis of well-defined criteria for coincident measurements between the instruments. In addition 

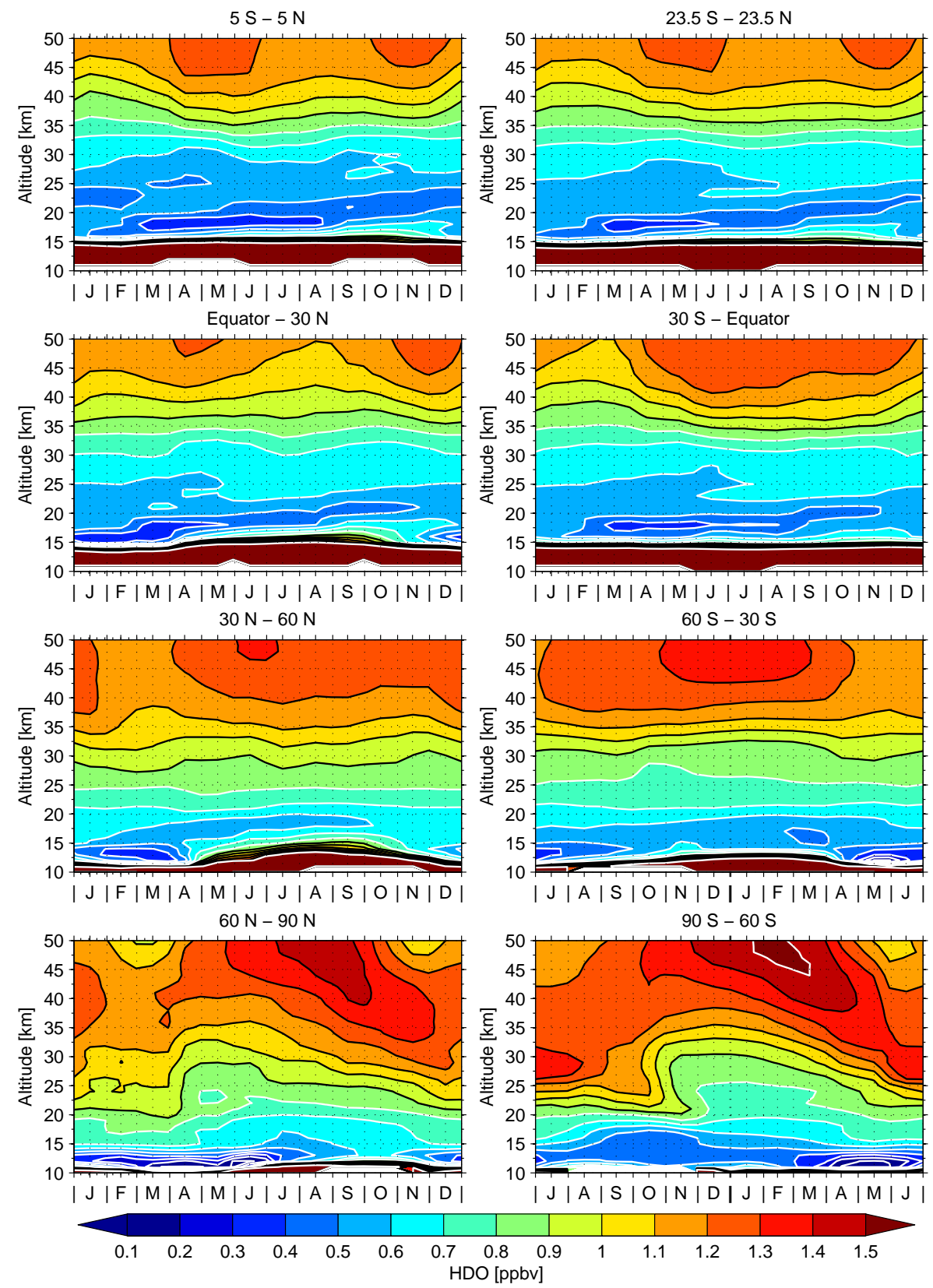

Fig. 1. Mean annual cycle of HDO for different latitude bands derived from the Envisat/MIPAS observations between June 2002 and March 2004. Please observe that the time axis of the panels that show the annual cycle in the mid-latitudes and polar regions (last two rows) has been adjusted so that the summer season always occurs in the middle of those panels.

we use analyses of linear fits and correlations based on seasonal means to test the internal consistency of HDO data sets included in the comparison. As a complement we show a comparison of monthly mean profiles in the tropical region, which is of special scientific interest. In the following subsection the Odin/SMR and SCISAT/ACE-FTS HDO data sets are characterised.

\subsection{Contributing instruments}

\subsubsection{Odin/SMR}

Odin is a Swedish-led satellite mission in co-operation with Canada, France and Finland. The satellite was launched on 20 February 2001 into a sun-synchronous and nearterminator orbit at an altitude of $600 \mathrm{~km}$. When the satellite was launched it crossed the equator at 18:00 LT on the 
ascending node and at 06:00 LT on the descending node. These crossing times have shifted by almost an hour as the orbit altitude has gradually decreased due to atmospheric drag. The Sub-Millimetre Radiometer is one of two instrument on board the Odin satellite. It measures thermal emission at the atmospheric limb with a $1.1 \mathrm{~m}$ telescope in several frequency bands between $486 \mathrm{GHz}$ and $581 \mathrm{GHz}$ as well as around $119 \mathrm{GHz}$ (Frisk et al., 2003). Measurements by Odin/SMR are nominally performed along the orbital track providing a latitude coverage between $82.5^{\circ} \mathrm{S}$ and $82.5^{\circ} \mathrm{N}$. Since 2004, SMR performs also observations off the orbital track during certain seasons as permitted by sun angle constraints, allowing full coverage from pole to pole. HDO information is retrieved from measurements of the $490 \mathrm{GHz}$ band that covers a HDO emission line that is centred at $490.597 \mathrm{GHz}$ (Urban et al., 2007). Measurements of this band are not performed on a daily basis, but initially on 3-4 days per month. After a major rearrangement of the SMR measurement schedule in April 2007 the observation rate increased to 8-9 days a month. The $490 \mathrm{GHz}$ band measurements are part of a stratosphere-mesosphere mode employing scans from $7 \mathrm{~km}$ to $110 \mathrm{~km}$. With a scanning velocity of $0.75 \mathrm{~km} \mathrm{~s}^{-1}$ it takes almost $140 \mathrm{~s}$ to perform a complete limb scan. This translates into a horizontal sampling of approximately one scan per $1000 \mathrm{~km}$. The integration time for an individual tangent view is approximately $1.85 \mathrm{~s}$. Combined with the detector read-out times the vertical sampling amounts to $3 \mathrm{~km}$. The retrieval of HDO employs a non-linear scheme of the Optimal Estimation Method (OEM, Rodgers, 2000). Spectroscopic data is taken from the Verdandi database that combines data from the JPL (Jet Propulsion Laboratory, Pickett et al., 1998) line catalogue and HITRAN (Rothman et al., 2003), as well as some other sources (Eriksson, 1999). HDO information can roughly be retrieved in the altitude range between $20 \mathrm{~km}$ and $70 \mathrm{~km}$ with an altitude resolution of $3 \mathrm{~km}$ to $4 \mathrm{~km}$ (Urban et al., 2004, 2007). The limiting factor at the lower altitude end are the increasing water vapour absorption with decreasing altitude and limitations of the signal-to-noise ratio. This ratio determines also the upper altitude limit of the retrieval where the HDO emission line gets very narrow. The random noise error of a single profile retrieved is in the order of $20 \%$ to $40 \%$ in the altitude range between $20 \mathrm{~km}$ and $50 \mathrm{~km}$, i.e. similar to the MIPAS data set. In the comparison we use data that has been processed with the latest official retrieval version 2.1 at the Chalmers University of Technology in Göteborg, Sweden.

\subsubsection{SCISAT/ACE-FTS}

The SCISAT (or SCISAT-1) satellite was launched on $12 \mathrm{Au}-$ gust 2003 into a high inclination $\left(74^{\circ}\right)$ orbit with an altitude of $650 \mathrm{~km}$, providing overall a latitudinal coverage between $85^{\circ} \mathrm{S}$ and $85^{\circ} \mathrm{N}$. The orbit has been optimised for observations in the polar regions and mid-latitudes. Like Odin, the ACE mission carries two instruments on board. Similar to MIPAS, the ACE-FTS instrument is a high-resolution (i.e. $0.02 \mathrm{~cm}^{-1}$ ) Fourier transform spectrometer that performs measurements in the spectral range between $750 \mathrm{~cm}^{-1}$ and $4400 \mathrm{~cm}^{-1}(2.3 \mu \mathrm{m}$ to $13.3 \mu \mathrm{m})$. The instrument employs the solar-occultation technique measuring the attenuation of sunlight by the atmosphere during sunset and sunrise, yielding up to 30 observations per day. ACE-FTS scans the atmosphere in the altitude range between $\sim 5 \mathrm{~km}$ and $150 \mathrm{~km}$. The vertical sampling varies from around $1 \mathrm{~km}$ in the middle troposphere to roughly $2-3.5 \mathrm{~km}$ in the altitude range between $10 \mathrm{~km}$ and $20 \mathrm{~km}$ and to $5-6 \mathrm{~km}$ in the upper stratosphere and mesosphere. The instrument has a field of view of $1.25 \mathrm{mrad}$ which coverts to about 3-4 km depending on altitude and observation geometry.

The retrieval of ACE-FTS observations uses a "globalfit" approach (Carlotti, 1988) that employs an unconstrained Levenberg-Marquardt non-linear least-squares method. The present comparison employs the "HDO update" data set that has been derived with a slightly modified setup of the original retrieval version 2.2 (Nassar et al., 2007). This retrieval version employs 24 microwindows in the wave number intervals between $1402-1498 \mathrm{~cm}^{-1}(6.7-7.1 \mu \mathrm{m})$ and $2612-$ $2673 \mathrm{~cm}^{-1}(3.7-3.8 \mu \mathrm{m})$ to derive information on HDO, typically covering altitudes from $5.5 \mathrm{~km}$ to $37.5 \mathrm{~km}$. The vertical resolution of this set of data is determined by the instrument's FOV and vertical sampling of the atmosphere, typically amounting to $3-4 \mathrm{~km}$. The lower limit of the retrievals is determined mainly by cloudiness, while the uppermost retrieval altitude is determined by the signal-to-noise ratio of the measurements. The random noise error of an individual profile retrieved is of the order of $10 \%$. Unlike the MIPAS retrieval the ACE-FTS retrieval uses spectroscopic data from the 2004 compilation of HITRAN (Rothman et al., 2005).

\subsection{Profile-to-profile comparisons}

\subsubsection{Methodology}

For the profile-to-profile comparisons we consider observations by two instruments as coincident when they meet the following criteria: (1) a spatial separation of less than $500 \mathrm{~km}$ and (2) a temporal separation that does not exceed $6 \mathrm{~h}$. These criteria represent a trade-off between a sufficient number of coincident measurements to draw significant conclusions and the avoidance of, in particular, spatial variations that could significantly influence the comparison. As the diurnal variation of HDO in the stratosphere is insignificant, a more relaxed time criteria could be used but tests showed that the results are virtually the same. In cases with multiple coincidences, the one located closest in space was used.

Prior to the comparison the data sets were screened to identify retrieved profiles or individual data points whose quality was not sufficient. In a first step this screening was based on the recommendations of the individual data processing teams. For the MIPAS data set this concerned the 
visibility flag and the averaging kernel diagonal criterion. For the retrieved data at a given altitude the visibility flag indicates interference by clouds based on a cloud index (Spang et al., 2004). This index is the ratio between the mean radiances in two spectral intervals of the measured spectra (788.20-796.24 $\mathrm{cm}^{-1}$ versus $\left.832.30-834.4 \mathrm{~cm}^{-1}\right)$. Investigations have shown that for any cloud index below 4 the presence of clouds cannot be excluded. In these cases the visibility flag is set to 0 and the retrieved data is omitted, effectively resulting in a clear sky bias. As a consequence the number of available data points typically decreases rapidly below the tropopause. In addition data have been used only if the diagonal element of the averaging kernel matrix exceeded an empirical threshold value of 0.03 , ensuring that the retrieved data represents the state of the atmosphere and is not dominated by retrieval constraints. The Odin/SMR data set has been screened according to the retrieval quality flag and the measurement response to the retrieved values. The retrieval quality flag indicates if a profile shall be used for scientific analysis based on the cost function, convergence and the regularisation of the retrieval along with the retrieved pointing offset. A measurement response of at least $70 \%$ was required in order to minimise the influence of the a priori information used in the SMR OEM retrieval (e.g. Rodgers, 2000; Eriksson et al., 2005). For ACE-FTS data issues listed on the "data issues page" https://databace.uwaterloo. $\mathrm{ca} /$ validation/data_issues_table.php were taken into account and the affected data discarded. Negative volume mixing ratios (VMRs) were not filtered in this analysis as these values can be a result of the retrieval due to measurement noise, in particular at the hygropause and the lower and upper boundaries where retrievals are possible. Finally the data sets were inspected visually to remove data points that were far outside the expected range of HDO VMRs and therefore can potentially influence the results of the bias determination. Typically this concerned only a handful profiles of the individual data sets.

As the individual satellite data sets are provided on different altitude grids the coincident profiles were interpolated on a regular $1 \mathrm{~km}$ altitude grid for the comparison. The vertical resolution of the HDO profiles retrieved from the MIPAS measurements is somewhat lower than the vertical resolution of the ACE-FTS and SMR data. For a large part of the stratospheric altitudes that are of concern here the HDO distribution is rather smooth. Here, the profiles can be compared directly despite those differences in the vertical resolution of the individual data sets. However in altitude layers where the HDO distribution is more structured, e.g. around the hygropause or stratopause, a direct comparison of the profiles may not always be appropriate and then the differences in the vertical resolution need to be taken into account. To study the influence of the different vertical resolutions on the comparison results the SMR and ACE-FTS profiles were degraded to the vertical resolution of the MIPAS profiles, following the method of Connor et al. (1994):
$\hat{x}_{\mathrm{c}}=x_{\mathrm{a}}+\mathbf{A} \cdot\left(\hat{x}_{\mathrm{h}}-x_{\mathrm{a}}\right)$.

Here $\hat{x}_{\mathrm{c}}$ represents the degraded and $\hat{x}_{\mathrm{h}}$ the high vertically resolved SMR or ACE-FTS profile, while $x_{\mathrm{a}}$ and $\mathbf{A}$ describe the a priori profile and the averaging kernel matrix of the MIPAS HDO retrieval, respectively. The reader may be reminded at this point that in the MIPAS retrieval the a priori profile serves only the purpose of constraining the shape or smoothness of a retrieved profile, different to the OEM approach were the a priori profile is also used to constrain the retrieved abundances. The coincident profiles from SMR and ACE-FTS were only compared directly as their vertical resolutions are very similar in the altitude range where these two data sets overlap.

At a given altitude the bias $B$ between two coincident data sets nos. 1 and 2 comprising $n$ coincidences is calculated as

$B=\frac{1}{n} \cdot \sum_{i=1}^{n} b_{i}$

where $b_{i}$ denotes the difference between each individual pair of coincident data points, either in absolute terms

$b_{i}=b_{i, \mathrm{abs}}=\hat{x}_{1, i}-\hat{x}_{2, i}$

or in relative terms

$b_{i}=b_{i, \mathrm{rel}}=\frac{\hat{x}_{1, i}-\hat{x}_{2, i}}{\left(\hat{x}_{1, i}+\hat{x}_{2, i}\right) / 2}$.

Here $\hat{x}$ refers to the retrieved HDO data from the individual data sets. The relation for the relative deviations is based on the assumption that satellite measurements might have large uncertainties, so that it is more convenient to refer to the mean of the two data sets involved, rather than to one specific data set (e.g. Randall et al., 2003; Dupuy et al., 2009). Additional information on the comparison is supplied in form of the de-biased standard deviation and the standard error of the mean (SEM). The de-biased standard deviation $\sigma$ is represented by the standard deviation of the bias-corrected deviations between two data sets compared:

$\sigma=\sqrt{\frac{1}{n-1} \cdot \sum_{i=1}^{n}\left(b_{i}-B\right)^{2}}$.

This quantity serves as a measure of the combined precision of the two data sets that are compared (von Clarmann, 2006), particularly in cases where a complete random error budget assessment is not available for all involved instruments, as in the present study. The standard error of the mean provides information on the significance of the derived bias between two data sets and is calculated as:

$\mathrm{SEM}=\frac{\sigma}{\sqrt{n}}$. 

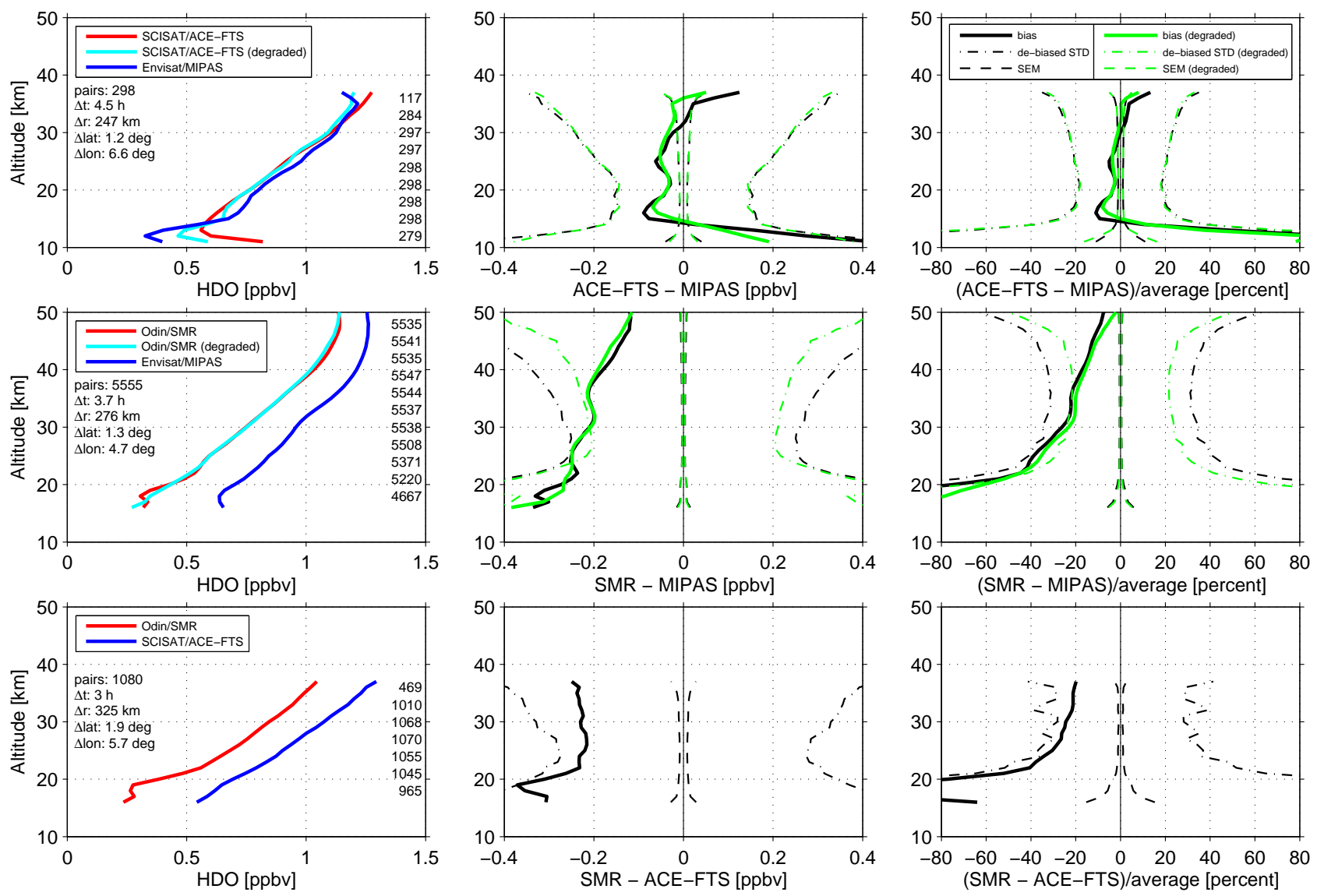

Fig. 2. Profile-to-profile comparisons of coincident HDO observations between MIPAS and ACE-FTS (upper panels), MIPAS and SMR (middle panels) and SMR and ACE-FTS (lower panels). The panels on the left-hand side show the mean profiles based on the coincident sets of data. The absolute biases are shown in the middle panels, the relative biases are given in the panels on the right-hand side. The dash-dotted lines represent the estimated combined precision of the data sets under comparison, while the dashed lines indicate the standard error of the derived biases. In the middle and right-hand panels the black lines show the results of direct comparisons, while green is used for the comparisons which involve the degradation of the vertical resolution of one data set.

\subsubsection{Results}

Figure 2 shows the results of the profile-to-profile comparisons between MIPAS and ACE-FTS (upper panels), MIPAS and SMR (middle panels) and SMR and ACE-FTS (lower panels). The panels on the left-hand side show the mean profiles based on the coincident pairs of data. These panels contain on the left information on the number of coincident profiles as well as their average separation in terms of time, distance, latitude and longitude. On the right the number of coincident pairs at a given altitude are indicated every $3 \mathrm{~km}$. In the middle panels the bias between two data sets is shown in absolute terms (solid lines), the right panels give the relative bias. In these two panels the results of direct comparisons are shown in black, if the vertical resolution of one data set has been degraded the results are given in green. The dash-dotted lines represent the estimated combined precision of the compared data sets on the basis of the de-biased standard deviation $\sigma$ (Eq. 7), comprising contributions from the measurement noise and the small temporal and spatial mismatch of the coincidences. The dashed lines indicate the standard error of the bias according to Eq. (8). The reader may be reminded at this point that the absolute and relative bias is calculated from each individual pair of coincident profiles which can lead to some apparent discrepancies in the comparison between mean profiles, as visible in Fig. 2.

Based on the coincidence criteria defined in Sect. 3.2.1 we found 298 pairs of coincident observations of MIPAS and ACE-FTS which were on average separated by $4.5 \mathrm{~h}$ in time and $250 \mathrm{~km}$ in distance As the ACE-FTS commissioning phase just ended in January 2004 and the MIPAS measurements with full spectral resolution ceased in March 2004 the temporal overlap between both data sets is very limited. During the overlap period the ACE-FTS observations were focusing on the Arctic. A majority of the coincident measurements occurred in the latitude range between $75^{\circ} \mathrm{N}$ and $80^{\circ} \mathrm{N}$, while the lowest latitude was $55^{\circ} \mathrm{N}$. The comparison for this limited period of time and region exhibits a 
favourable result. The deviations are typically smaller than $0.1 \mathrm{ppbv}$ or $10 \%$ and well within the estimated precision boundaries. Exceptions can be found at the lower and upper altitude end where comparisons were possible. Here also the significance of the derived bias decreases. Degrading the ACE-FTS data onto the altitude resolution of MIPAS clearly improves the comparison result at these altitudes. For most altitudes the MIPAS observations show higher abundances than the coincident measurements by ACE-FTS. There is a prominent oscillation in the bias between $15 \mathrm{~km}$ and $30 \mathrm{~km}$. The consistency between both data sets does not change significantly when the comparison is made separately for the polar vortex inside and outside. The differences in the spectral databases used in the MIPAS and ACE-FTS retrievals do not play a significant role for the comparison between the two instruments. The changes in the line intensity parameter from the HITRAN-2000 to the HITRAN-2004 database were less than $1 \%$ for the microwindows employed in the MIPAS retrieval. A sensitivity study with the MIPAS retrieval using the HITRAN-2004 data exhibited a slight decrease $(0.01 \mathrm{ppbv}$ at the maximum, $0.003 \mathrm{ppbv}$ on average) of the retrieved HDO VMRs compared to the standard retrieval. This can only explain a small part of the generally positive differences between the MIPAS and ACE-FTS HDO retrievals.

The profile-to-profile comparison between MIPAS and SMR covers the entire time period in which the full spectral resolution measurements by MIPAS were possible, i.e. coincidences were found throughout June 2002 to March 2004. The results shown in Fig. 2 represent the global average over all coincidence cases. Most of those where found in the polar regions with a decreasing number towards the tropics. In the month domain the highest number of coincident measurements could be obtained in December however none in March, May and August. On the global average the SMR data set exhibits a dry bias compared to the MIPAS data at all altitudes addressed here. The results are almost identical for the direct comparison and the comparison using SMR data that have been degraded to the vertical resolution of MIPAS. The bias maximises below $20 \mathrm{~km}$ with values between $0.25 \mathrm{ppbv}$ and $0.4 \mathrm{ppbv}$ or more than $80 \%$ in relative terms. This bias can be attributed to a substantial fraction of data with large random noise errors. Between $16 \mathrm{~km}$ and $20 \mathrm{~km} 20 \%$ to $55 \%$ of the data exhibits relative errors larger than $100 \%$. From $20 \mathrm{~km}$ to $50 \mathrm{~km}$ the bias decreases gradually from $0.25 \mathrm{ppbv}$ to nearly a half of that. The relative bias decreases from about $60 \%$ at $20 \mathrm{~km}$ to less than $10 \%$ at $50 \mathrm{~km}$. Looking at different seasons and latitude bands does not change the overall picture clearly indicating that the bias is a systematic feature (not shown here).

Similar structures that were visible in the comparison between MIPAS and SMR can also be observed when coincident observations of ACE-FTS and SMR are compared with each other. Above $20 \mathrm{~km}$ the SMR observations show again a low bias of about $0.2 \mathrm{ppbv}$ to $0.25 \mathrm{ppbv}$ compared to the ACE-FTS measurements on a global scale. Coincident measurements between February 2004 and September 2010 were used in the comparison. Due to the characteristics of the SCISAT orbit, the bulk of the coincidences were found in the mid-latitudes and polar regions. Most coincident measurements of both instruments were available around the equinoxes.

\subsection{Seasonal comparisons}

\subsubsection{Methodology}

In this section we consider comparisons of latitudinal cross sections for the individual seasons. For this the data sets were averaged over latitude bins of $10^{\circ}$ (centred at $85^{\circ} \mathrm{S}, 75^{\circ} \mathrm{S}, \ldots$, $75^{\circ} \mathrm{N}$ and $85^{\circ} \mathrm{N}$ ) for the individual seasons, i.e. MAM (March, April and May), JJA (June, July and August), SON (September, October and November) and DJF (December, January and February). All data for a given season were averaged together directly, i.e. no intermediate monthly averages were calculated. As for the annual distributions shown in Fig. 1, a minimum of 25 individual measurements were required for an average to be considered, in order to avoid spurious data points in the latitudinal cross sections. The data were again interpolated on a regular vertical grid of $1 \mathrm{~km}$. For the MIPAS and SMR data sets we considered the time period between June 2002 and February 2004, implying that all seasons except MAM are sampled twice. As ACE-FTS observations just started in 2004 we chose the time periods from June 2004 to February 2006 and from June 2006 to February 2008 instead. The choice of two time periods was motivated by the smaller number of observations by ACE-FTS as compared to the other instruments due to the utilisation of the solar occultation technique. These particular periods were selected with regard to the phase of the quasi-biennial oscillation (QBO), which was quite similar for all three time periods employed, i.e. the QBO period was rather close to 24 months during these years. A third possible time period from June 2008 to February 2010 was disregarded because the QBO cycle exhibited clearly a much longer period than before. Overall the choice of the ACE-FTS time periods will minimise the influence of QBO effects on the results of the seasonal comparison. However there is still a possibility that the comparison of the ACE-FTS results with the other two instruments might be affected by any change in the temporal behaviour of HDO throughout the time periods considered. Opposite to profile-to-profile comparisons the SMR and ACE-FTS were not degraded to the vertical resolution of the MIPAS retrieval. On the one hand it is difficult to provide the appropriate convolution data for an entire dataset, on the other hand the data averaging tends to reduce the differences in the vertical resolution among the individual data set.

To describe the significance of the derived cross sections we use, as for the biases in the profile-to-profile comparisons, 
the SEM. For the particular application here the standard error is denoted as $\epsilon$ and derived as follows:

$\epsilon=\sqrt{\frac{1}{k \cdot(k-1)} \cdot \sum_{i=1}^{k}\left(\hat{x}_{i}-\overline{\hat{x}}\right)^{2}}$.

$k$ describes the number of retrieved data points $\hat{x}$ of an individual data set that fall into a given latitude bin for a specific season and altitude. $\overline{\hat{x}}$ denotes the average over the entire ensemble of these data points. To provide a quantitative measure of the consistency of the latitudinal cross sections derived from two instruments at a given altitude and season we supply the parameter of a linear fit and the correlation coefficient. The linear fit parameter $a$ (intercept) and $b$ (slope) were obtained by minimising the following regression relation:

$\sum_{i=1}^{l} \frac{\left(x_{1, i}-a-b \cdot x_{2, i}\right)^{2}}{\epsilon_{1, i}^{2}+\left(b \cdot \epsilon_{2, i}\right)^{2}}$.

This relation considers the standard error $\epsilon$ (Eq. 9) that is associated with the averages $x$ for a given season and latitude bin for the data sets nos. 1 and 2 . $l$ denotes the number of latitude bins. In practice, the determination of the linear fit parameter employed an iterative scheme. In the first iteration step only the errors of data set no. $2 \epsilon_{2}$ were considered. The resulting regression line was then used to linearly map the errors of data set no. $1 \epsilon_{1}$ into the space of data set no. 2. The combined error of both data sets was then used for the second iteration step. The procedure was iterated until convergence. The correlation coefficients $r$ were calculated by:

$r=\frac{\sum_{i=1}^{l}\left(x_{1, i}-\bar{x}_{1}\right) \cdot\left(x_{2, i}-\bar{x}_{2}\right)}{\sqrt{\sum_{i=1}^{l}\left(x_{1, i}-\bar{x}_{1}\right)^{2} \cdot\left(x_{2, i}-\bar{x}_{2}\right)^{2}}}$.

$\bar{x}$ describes the mean over all latitude bins for a given season for the individual data sets. The calculation of the correlation coefficients here does not consider any error estimates. We do not want to prove if two data sets are correlated by chance but simply show that the expected high correlation between the latitudinal cross sections observed by two instruments is present. As before, all given variables are implicitly depending on altitude.

\subsubsection{Results}

Figure 3 and 4 present the latitudinal cross sections for the different seasons that were derived from the individual measurements. Figure 3 focuses on altitudes from $12 \mathrm{~km}$ to $24 \mathrm{~km}$ while Fig. 4 addresses altitudes above. The dashed lines represent the standard error $\epsilon$ of the cross sections according to Eq. (9). Typically several thousand individual MIPAS measurements contributed to the average for a given latitude bin, altitude and season (lowest numbers in MAM as well as at the lowest altitudes). This is roughly a factor of 30 more than for SMR and ACE-FTS. The ACE-FTS latitudinal cross sections exhibit some gaps indicating that there was no or not sufficient coverage of the latitude range in question. The latitudinal distribution observed by MIPAS and ACEFTS at $12 \mathrm{~km}$ are fairly consistent during all seasons. Still, in relative terms, the deviations (referenced to the mean of both data sets) can amount up to $100 \%$ in MAM with ACE-FTS typically showing higher abundances. At $15 \mathrm{~km}$ MIPAS and ACE-FTS also show good consistency with the relative deviations typically being within $30 \%$. Higher up, at $18 \mathrm{~km}$, also the SMR observations contribute to the comparisons. The SMR cross sections are a bit more noisy than for the other instruments and in JJA even negative values can be observed. However the overall distribution is similar, still the absolute deviations can exceed 0.4 ppbv. The MIPAS and ACE-FTS latitudinal cross sections fit best in MAM. Notable differences between these two data sets are found in the Antarctic in JJA and SON. There the ACE-FTS observations exhibit a pronounced drop in the HDO VMRs, while this behaviour is not apparent in the MIPAS observations. In JJA also the SMR measurements exhibit such a drop, but its size is smaller than in the ACE-FTS observations. Similar to MIPAS, no drop is visible in the SMR observation for SON. Deviations between MIPAS and ACE-FTS are also evident in the tropics, especially in JJA and DJF. Otherwise the agreement between the MIPAS and ACE-FTS VMRs is typically within $20 \%$. The latitudinal structures observed by all instruments at 24 , 30 and $36 \mathrm{~km}$ exhibit overall a high degree of consistency. Typically the MIPAS VMRs are slightly higher than those of ACE-FTS, as seen already in the profile-to-profile comparison in Fig. 2. The relative deviations between those two data sets do in general not exceed $10 \%$ at these altitudes. The absolute deviations between MIPAS and SMR at $30 \mathrm{~km}$ are on average slightly lower than $0.2 \mathrm{ppbv}$. This average deviation is smaller than at $24 \mathrm{~km}(0.24 \mathrm{ppbv})$ and $36 \mathrm{~km}(0.21 \mathrm{ppbv})$, a feature that was also visible in profile-to-profile comparisons. At $36 \mathrm{~km}$ more pronounced deviations between MIPAS and ACE-FTS can be observed in SON in the southern hemisphere tropical and mid-latitudes. In the upper stratosphere the differences between MIPAS and the SMR data set decrease noticeably in terms of absolute abundances compared to the lower altitudes. With the exception of MAM at $48 \mathrm{~km}$ the latitudinal structures remain to fit favourably. During this season SMR exhibits also higher VMRs than MIPAS in some latitude bins.

Example scatter plots using the average HDO abundances for different latitude bins for all possible instrument combinations and seasons are shown in Fig. 5. Here the altitudes $18 \mathrm{~km}$ (lower panels), $30 \mathrm{~km}$ (middle panels) and $42 \mathrm{~km}$ (upper panels) are shown. Comparisons between MIPAS and ACE-FTS are given by blue data points, red data points show the comparison between MIPAS and SMR and green data points are used for the comparison between SMR and ACEFTS. The data set named first uses the abscissa of the graph while the data set named last uses the ordinate. Small error bars around the data points indicate the standard error $\epsilon$ of 

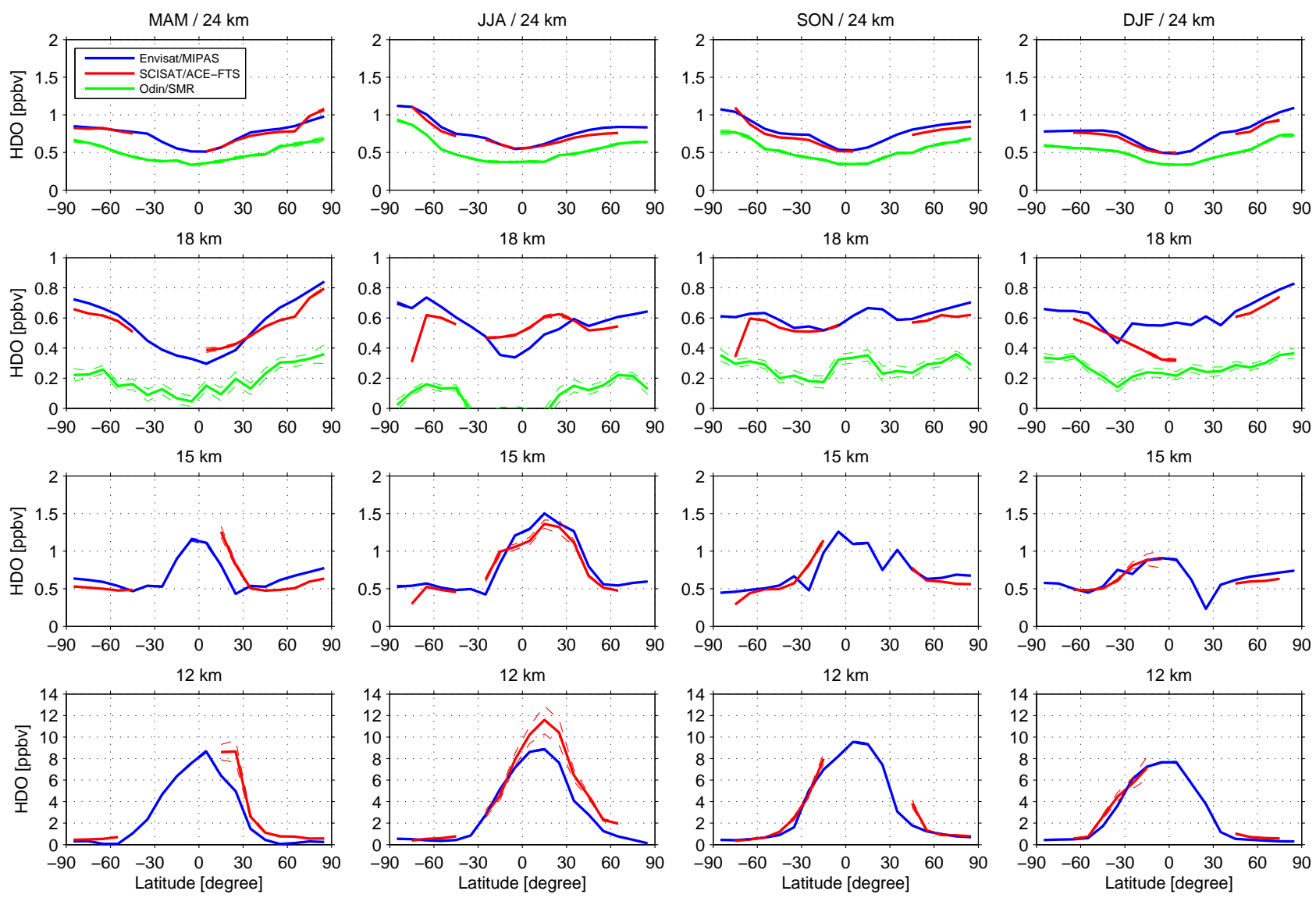

Fig. 3. Latitudinal cross sections of HDO from MIPAS (blue), SMR (green) and ACE-FTS (red) observations for different seasons and altitudes from $12 \mathrm{~km}$ to $24 \mathrm{~km}$. The data were averaged over latitude bins of $10^{\circ}$. The MIPAS and SMR cross sections are based on observations from June 2002 to February 2004, for ACE-FTS the time periods June 2004-February 2006 and June 2006-February 2008 were used. Dashed lines indicate the standard error of the derived cross sections. Please note that the y-axis range changes with altitude.

the data (Eq. 9). The solid lines represent the linear fits to the scatter data (according to Eq. 10) and the black dashed line indicates the ideal fit (intercept $=0$, slope $=1$ ). The comparisons at $18 \mathrm{~km}$ exhibit a number of cases where the linear fits significantly deviate from the ideal case. In JJA the least agreement between the MIPAS and ACE-FTS latitudinal cross sections can be observed. Higher up the linear fits witness the overall good consistency between the individual data sets, as evident from the previous figures. Figure 6 summarises quantitatively the results of the linear fit analysis in terms of intercept (left panels) and slope (middle panels) for the altitude range between $10 \mathrm{~km}$ and $50 \mathrm{~km}$. In addition the correlation coefficients, according to Eq. (11), are shown in the right panels. The latitudinal cross sections of MIPAS and ACE-FTS compare very well above $20 \mathrm{~km}$ showing linear fit parameters that are close to an ideal fit. The correlations coefficients are almost everywhere above 0.9 in this altitude region. High correlation coefficients can also be observed between $10 \mathrm{~km}$ and $15 \mathrm{~km}$. There is a pronounced drop of the correlations in the altitude region from about $15 \mathrm{~km}$ to
$20 \mathrm{~km}$. This feature is characteristic for all comparisons between the individual instruments. The MIPAS and SMR latitudinal cross sections correlate nicely from about $20 \mathrm{~km}$ to $45 \mathrm{~km}$. Above, high correlations can even be seen for JJA and DJF, while especially for MAM the consistency is significantly reduced, as also evident from the line fit parameters. The comparison of the latitudinal cross sections derived from the SMR and ACE-FTS measurements yields also high correlation coefficients above $20 \mathrm{~km}$, in accordance to the other comparisons.

\subsection{Monthly comparisons in the tropics}

In this comparison we focus on four months, namely February, April, August and October. Only in these months ACEFTS observations cover the tropics as the ACE orbit is optimised for polar and mid-latitudes. Hence seasonal comparisons with ACE-FTS may be less appropriate in the tropics. For this comparison the data were averaged over the latitude range from $15^{\circ} \mathrm{S}$ to $15^{\circ} \mathrm{N}$ for a given month, considering data from the same time periods as used in the seasonal 

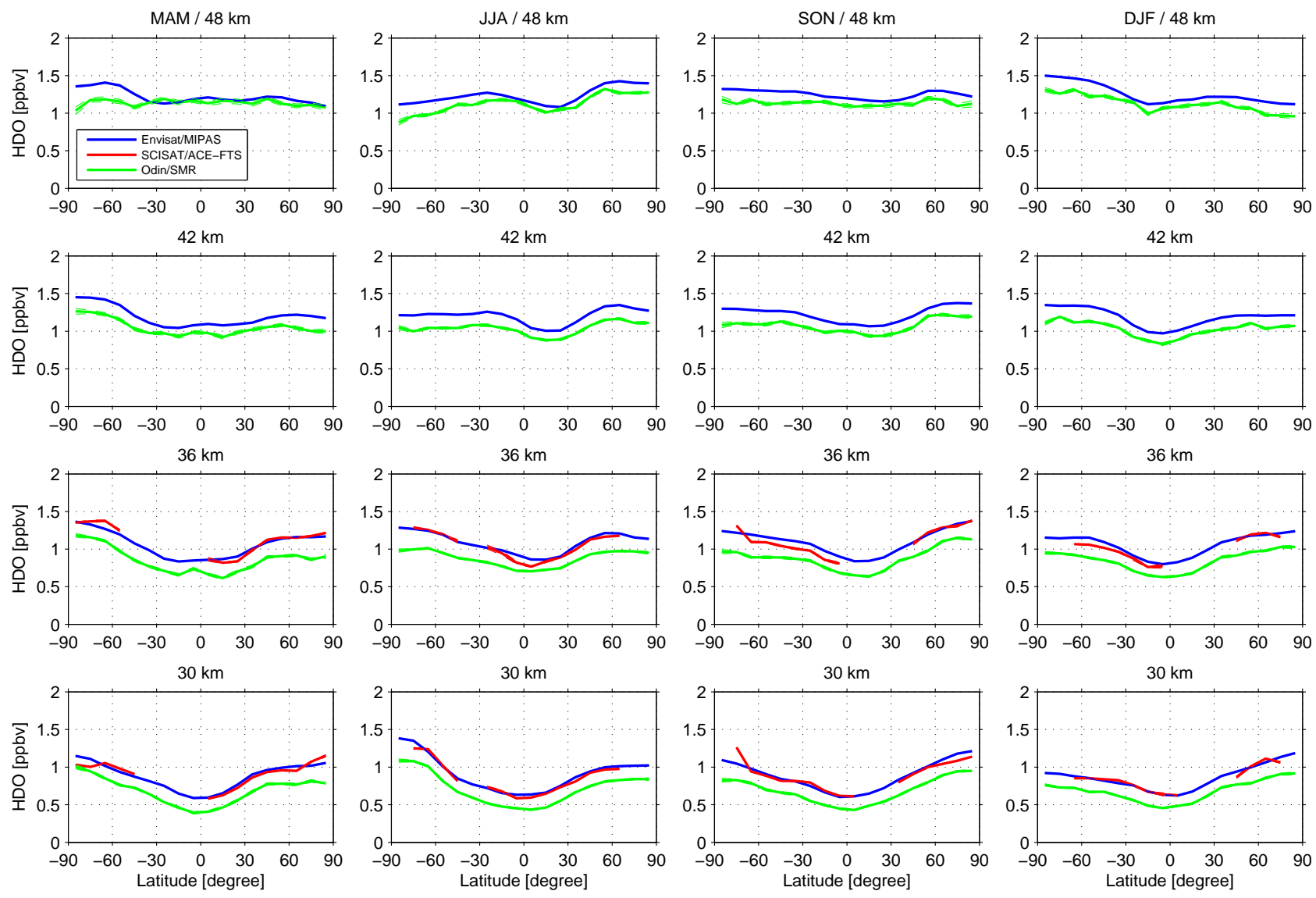

Fig. 4. As Fig. 3 but here for the altitudes from $30 \mathrm{~km}$ to $48 \mathrm{~km}$.

comparisons for the individual instruments (see Sect. 3.3.1). As before, at least 25 individual measurements were required for an average to be considered. Like for the seasonal comparisons, ACE-FTS and SMR data were not degraded to the vertical resolution of the MIPAS data set. Figure 7 shows the tropical monthly mean profiles in the altitude region between $10 \mathrm{~km}$ and $50 \mathrm{~km}$. The dashed lines represent the standard error of the mean profiles. In February the MIPAS observations exhibit rather constant VMRs around $20 \mathrm{~km}$, while the SMR and ACE-FTS measurements show a distinct hygropause at $18 \mathrm{~km}$. The bias between the SMR and ACE-FTS observations is here much smaller than particularly in the altitude range between $20 \mathrm{~km}$ and $25 \mathrm{~km}$. Here the SMR observations exhibit a very structured HDO distribution, comprising a local maximum at $22 \mathrm{~km}$ and a local minimum close to $25 \mathrm{~km}$. A similar structure is evident in the ACE-FTS observations, but the extrema are less pronounced. Above $30 \mathrm{~km}$ the bias between SMR and the other observations clearly decreases as seen in the earlier comparisons. A nice agreement in the vertical structures observed by all instruments is found in April, with a rather constant low bias by SMR compared to MIPAS and ACE-FTS. The hygropause is located at $18 \mathrm{~km}$ to $19 \mathrm{~km}$. As in February the SMR observations exhibit a local maximum around $22 \mathrm{~km}$ and a local minimum higher up at about $25 \mathrm{~km}$. The same features are also visible in the other observations, but for MIPAS at slightly different altitudes. In August the SMR and MIPAS measurements exhibit both a sharp hygropause structure. In the ACE-FTS observations the hygropause is rather smooth and located higher up compared to the other instruments. As in the previous months the SMR observations show distinct structures in the altitude range between $20 \mathrm{~km}$ and $30 \mathrm{~km}$. The local extrema are located somewhat higher up than in February and April, a consequence of the upward transport of the "tape recorder" signal. The VMRs observed by all three instruments during this month are rather constant in the altitude range between $24 \mathrm{~km}$ and $30 \mathrm{~km}$. Around $35 \mathrm{~km}$ the bias between the ACEFTS and MIPAS observations is larger than in the previous months. In October the MIPAS and ACE-FTS observations exhibit the hygropause at $21 \mathrm{~km}$. The ACE-FTS profile is less structured than the MIPAS profile in the altitude range between roughly $18 \mathrm{~km}$ and $35 \mathrm{~km}$. The hygropause in the SMR observations occurs below $20 \mathrm{~km}$. No local extrema are observed above $20 \mathrm{~km}$ where the shape of the profile is rather similar to ACE-FTS. The bias between SMR and MIPAS is rather constant between $20 \mathrm{~km}$ and $35 \mathrm{~km}$, decreasing 

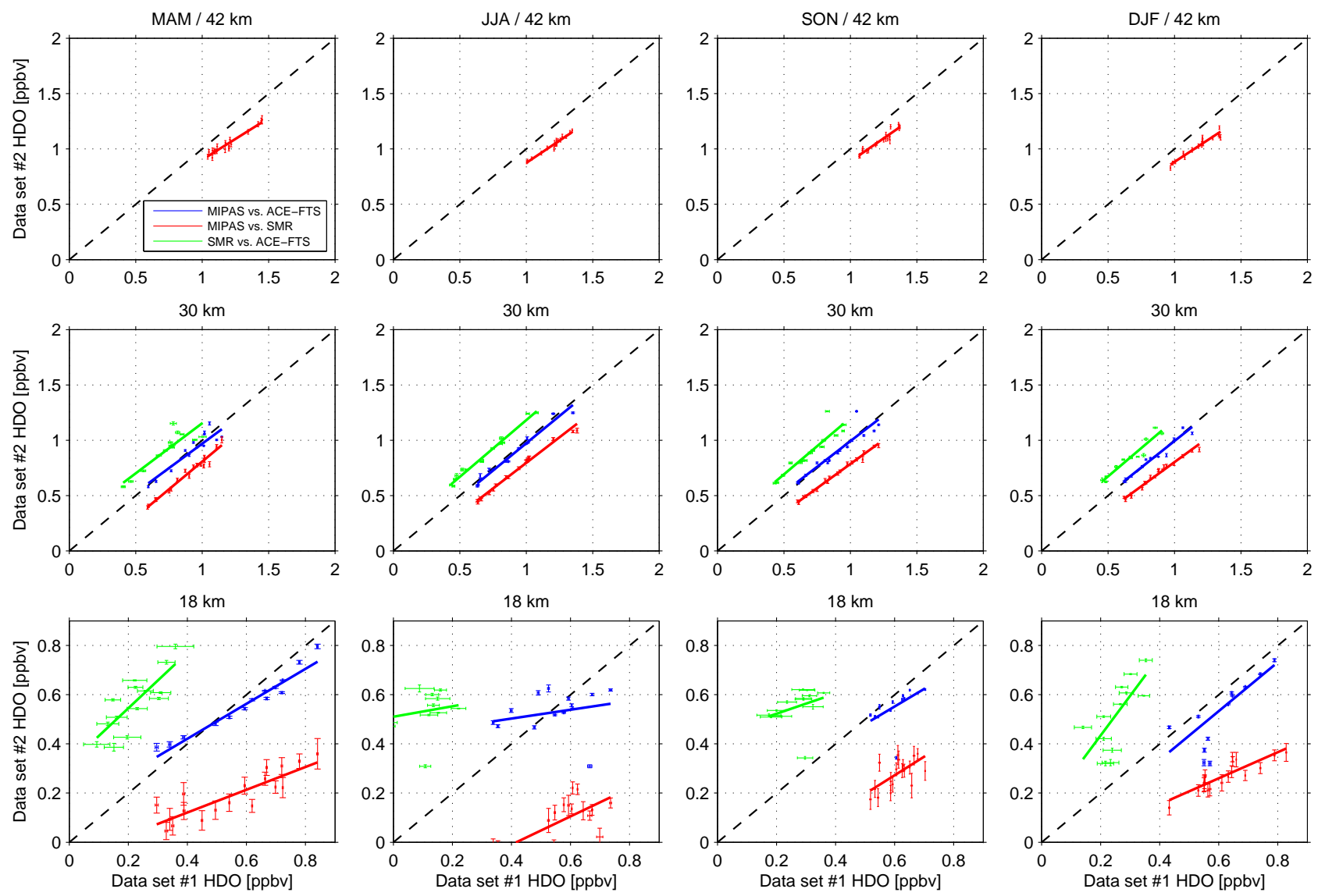

Fig. 5. Scatter plots based on the latitudinal cross sections at three representative altitudes for the different seasons. The comparison between MIPAS and ACE-FTS is shown in blue, MIPAS versus SMR is given in red while the comparison between SMR versus ACE-FTS uses green. The data set named first uses the abscissa, the latter one the ordinate. The solid lines represent the line fits for the individual comparisons. Note that different scales are used for the axes depending on altitude. The dashed line gives the ideal fit (intercept $=0, \mathrm{slope}=1$ ).

considerably at higher altitudes, as typical for all monthly comparisons considered here.

\section{Summary and discussion}

To assess the quality of the MIPAS HDO data set obtained with full spectral resolution from June 2002 to March 2004 comparisons with observations by Odin/SMR and SCISAT/ACE-FTS were performed. Overall the comparisons show favourable results, with very good consistency above $20 \mathrm{~km}$ and larger deviations at altitudes below.

The comparisons between MIPAS and ACE-FTS exhibit the largest deviations, both in absolute and relative terms, at the lowermost altitudes addressed here, i.e. below $15 \mathrm{~km}$. At some latitudes the data sets deviate by more than $100 \%$ in the seasonal comparisons at $12 \mathrm{~km}$. On average the relative deviation between MIPAS and ACE-FTS amounts to more than $40 \%$ at this altitude. At $15 \mathrm{~km}$ this average value has decreased to almost $15 \%$. One contribution to the deviations between MIPAS and ACE-FTS at these low altitudes can arise from the differences in vertical resolution, which are largest here and might effect the results of the seasonal comparisons. Still the profile-to-profile comparisons accounting for these differences also show the largest deviations between the two data sets below $15 \mathrm{~km}$. Up to $15 \mathrm{~km}$ the deviations between MIPAS and ACE-FTS are generally larger in the tropical region than in the extra-tropics. The influence of clouds in the upper tropical troposphere on the measurements plays a key role for these latitudinal differences. Measurements in the the infrared, as by MIPAS and ACEFTS, are significantly influenced by clouds. Hence, results retrieved from these observations exhibit a bias towards clear sky conditions. Results from observations in the microwave region, as those of SMR, are less affected by clouds. MIPAS and ACE-FTS even share some spectral information to derive HDO data. This, for itself, should in principle result in very similar cloud influence. However the two instruments use very different measurement techniques. As described in Sect. 3.2.1 a cloud index (Spang et al., 2004) is employed in the MIPAS retrieval to the detect and filter cloud influence. 

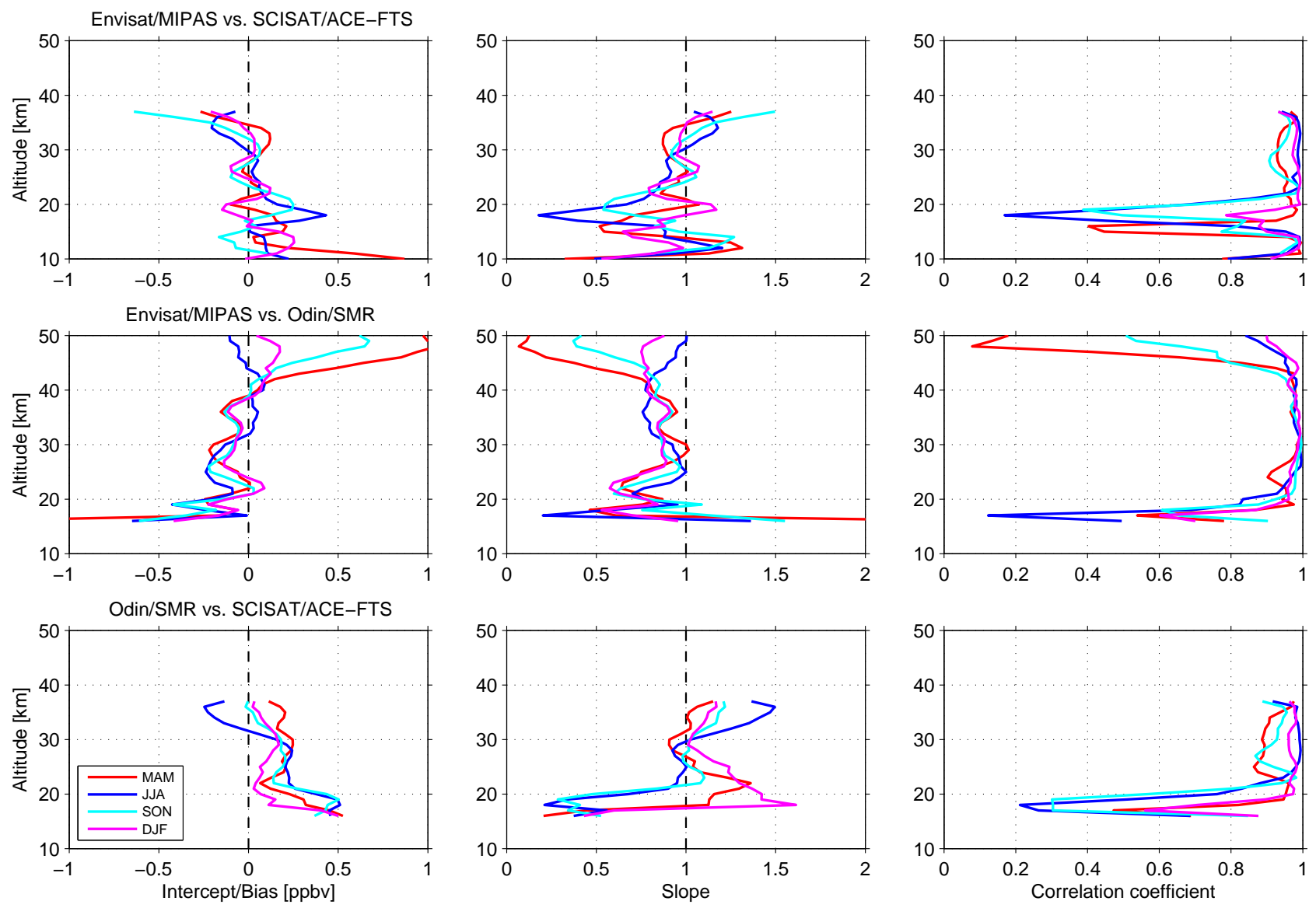

Fig. 6. Summary of the linear fit parameter and correlation coefficients derived from the seasonal comparisons of the latitudinal cross sections for the altitude range between $10 \mathrm{~km}$ and $50 \mathrm{~km}$. The upper panels show the results for the comparison between MIPAS and ACE-FTS, the comparison between MIPAS and SMR is shown in the middle panels. The lower panels summarise the results of the comparison between SMR and ACE-FTS. The dashed lines indicate the optimal line fit parameter.

In the ACE-FTS retrieval there is no explicit cloud filtering scheme, but the measurement approach contains an implicit filter. The pointing of the ACE-FTS measurements is controlled by a pointing mirror that locks on the Sun centre while the occultation is performed (Bernath et al., 2005). When clouds are in the line of sight and hide the view onto the Sun the ACE-FTS pointing mechanism fails and the scans are truncated. These basic differences in the measurement technique and cloud filtering result in different clear sky biases encountered by the MIPAS and ACE-FTS observations, which in turn bear significance for the derived results. In addition there are some spatial and temporal differences in the observational coverage by the individual instruments. Hence, with high probability, the observations by MIPAS, ACE-FTS and SMR do not cover the very same aspects of a cloudy scene and the associated HDO distribution. The same chain of arguments can be applied to differences between MIPAS and ACE-FTS that are observed in the seasonal comparisons at $18 \mathrm{~km}$ in the tropics. The monthly comparisons in February and August show also some larger deviations slightly above the TTL. Here, close to the hygropause, the differences in the vertical resolution of the MIPAS and ACE-FTS HDO data sets can still be of importance. Also, the cloud filtering at lower altitudes can influence these higher altitudes, as the information that goes into the retrieval is changed. Steinwagner et al. (2010) performed a sensitivity study in which they intentionally omitted data from tangent heights that the cloud filtering scheme would allow for scientific use. They found a small dependence between the minimum tangent height included in the MIPAS retrieval and the mean profile derived from the test data set. In the upper part of the TTL virtually no influence was found, but around $21 \mathrm{~km}$ the influence amounted to about $0.025 \mathrm{ppbv}$. The influence of minimum tangent height on the mean profile continued up to about $25 \mathrm{~km}$.

Pronounced differences between MIPAS and ACE-FTS can also be observed in the seasonal comparisons in the Antarctic in JJA and SON at $18 \mathrm{~km}$. Here the ACE-FTS observations exhibit a significant drop in the HDO abundances. Overall, this characteristic is visible in the altitude range 

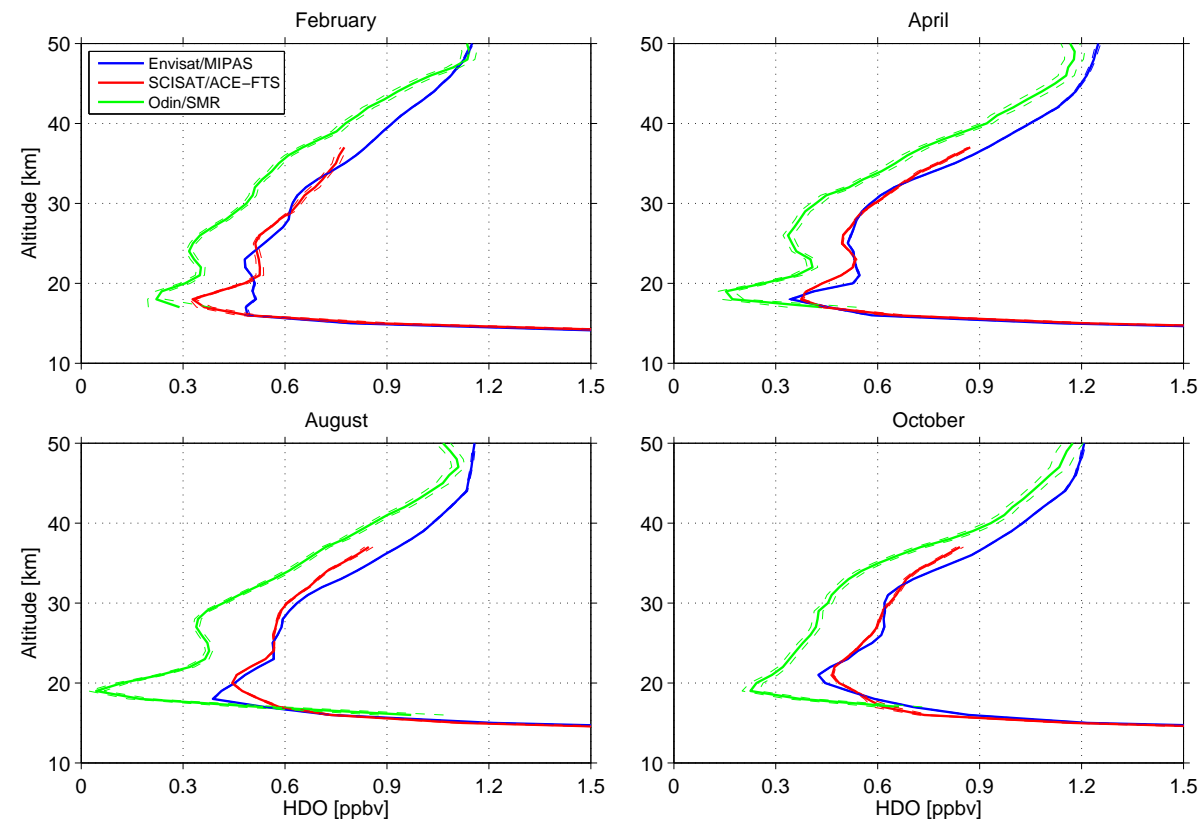

Fig. 7. Monthly mean profiles for the tropical region $\left(15^{\circ} \mathrm{S}-15^{\circ} \mathrm{N}\right)$ for February, April, August and October. The dashed lines indicate the standard error of the mean profiles.

between about $15 \mathrm{~km}$ and $23 \mathrm{~km}$. In the MIPAS observations, however, this feature is not present. The SMR observations exhibit such a drop only in JJA, but with a smaller magnitude as compared to the ACE-FTS observations. While on average the relative deviation between ACE-FTS and MIPAS is around $10 \%$ at $20 \mathrm{~km}$ the deviations rise up to about $50 \%$ in the Antarctic during winter and spring. As the very same characteristics are evident in a corresponding seasonal comparison of $\mathrm{H}_{2} \mathrm{O}$ (not shown here) it is natural to assume an influence from polar stratospheric clouds that occur at this location and time of year. Similar to tropospheric clouds the filtering of PSCs can cause differences in the results retrieved from the individual satellite observations. In addition, different time periods were used to compile the latitudinal cross sections for MIPAS, SMR (June 2002-February 2002) and ACE-FTS (June 2004-February 2006 and June 2006February 2008, see Sect. 3.3.1). Hence, pronounced differences in the PSC behaviour during these different time periods, especially in the dehydration effects from those PSCs that are made of water ice (type II, Kelly et al., 1989; Vömel et al., 1995), may provide an explanation for the disagreement in the Antarctic. Temperature analyses based on ECMWF (European Centre for Medium-range Weather Forecast) data indeed indicate differences in the conditions for PSC type II formation between the different time periods used to compile the latitudinal cross sections. For the ACEFTS periods the conditions for the formation of PSC type II were more favourable, especially in 2005 (not shown here). However, analysing the SMR observations for the same time periods as chosen for ACE-FTS yields qualitatively the same results as before, i.e. a drop in the HDO abundance is present in JJA, but not in SON (not shown here). Most of the ACEFTS data that goes into the seasonal averages of JJA and SON polewards of $70^{\circ} \mathrm{S}$ is obtained in August and September. Taking this into consideration by using monthly instead of seasonal means does not significantly reduce the deviations between ACE-FTS and the other data sets.

Above $20 \mathrm{~km}$ the MIPAS and ACE-FTS observations agree favourably at all latitudes. Up to $37 \mathrm{~km}$ where the ACE-FTS HDO data set derived with retrieval version 2.2 stops (the next version will extend into the $40 \mathrm{~km}$ to $50 \mathrm{~km}$ region), the HDO abundances typically agree within $10 \%$ (on average $\sim 5 \%$ ) for all seasons. In the majority of cases the MIPAS VMRs are on the high side, which to a small extent can be attributed to the different spectroscopic databases used in the MIPAS and ACE-FTS retrievals. Also inconsistencies between the spectroscopic parameter for the spectral regions that are exclusively used in the MIPAS (1250$1402 \mathrm{~cm}^{-1}$ ) and ACE-FTS (1483-1498 $\mathrm{cm}^{-1}$ and 2612 $2673 \mathrm{~cm}^{-1}$ ) HDO retrievals may be a contribution to this wet bias of the MIPAS data.

The comparisons between MIPAS and SMR above $20 \mathrm{~km}$ reveal a dry bias of the SMR measurements which slowly decreases with altitude. Up to about $30 \mathrm{~km}$ the bias is typically between $0.2 \mathrm{ppbv}$ and $0.3 \mathrm{ppbv}$ during all seasons except for the latitude range between $20^{\circ} \mathrm{S}$ and $20^{\circ} \mathrm{N}$ (below $25 \mathrm{~km}$ ) where smaller deviations can be observed. Between $30 \mathrm{~km}$ and $35 \mathrm{~km}$ the bias exhibits a local minimum on average somewhere between $0.15 \mathrm{ppbv}$ and $0.2 \mathrm{ppbv}$. Above $40 \mathrm{~km}$ the bias decreases most pronounced in the tropics to 
values around $0.1 \mathrm{ppbv}$ while in the Antarctic region in MAM and JJA again an increase can be observed. To understand the reasons for this bias of the SMR data set compared to the other instruments, a small sensitivity study with the SMR retrieval has been performed. This sensitivity study pointed towards the typical candidates, i.e. calibration and spectroscopic parameter, most important the line broadening parameter. Assuming an uncertainty of $5 \%$ in the line broadening parameter of the $490 \mathrm{GHz} \mathrm{HDO}$ emission line translates to an uncertainty of $0.05 \mathrm{ppbv}$ in the retrieved data in the altitude range between $20 \mathrm{~km}$ and $50 \mathrm{~km}$ (Urban et al., 2004). Worst case estimates of the uncertainty of the line broadening parameter based on the HITRAN spectroscopy database are considerably higher, explaining a large fraction of the bias observed. On the other hand, the MIPAS and ACE-FTS retrievals of HDO use some common spectral information for the retrieval of HDO. Even if slightly different parameters are used any significant error in those parameter will change the comparison result with respect to the SMR data set. Uncertainties in the line intensities and pressure broadening lead to an uncertainty of more than $0.05 \mathrm{ppbv}$ at $20 \mathrm{~km}$ in the MIPAS retrieval (Steinwagner et al., 2007). At $30 \mathrm{~km}$ the uncertainty is about $0.1 \mathrm{ppbv}$, at $40 \mathrm{~km} 0.15 \mathrm{ppbv}$. Thus, spectroscopic data play likely the dominant role in understanding the bias observed between SMR and the other instruments. Aside from the bias, the linear fit and correlation analysis of the latitudinal cross sections clearly indicates that a high degree of consistency exists in the structures observed among all three data sets that are compared here. Also, there is good agreement in the vertical structures observed by all instruments in the tropics between $20 \mathrm{~km}$ and $30 \mathrm{~km}$ where the "tape recorder" signal is transported upwards. The vertical distribution is more structured in the SMR observations than in the other measurements, likely because SMR has overall the best vertical resolution in this altitude region. In addition the comparisons with SMR allow the quality of the MIPAS data above $42 \mathrm{~km}$ to be evaluated, where the statistical error of the retrieved data significantly increases. This comparison exhibits a good agreement for SON and DJF, to a large extent also for JJA. Good consistency is also found in temporal structures as function of various latitude bins (not shown here). This puts some confidence into the MIPAS data set at these altitudes, however averaging over a larger set of observations is a prerequisite for scientific analyses.

\section{Conclusions}

The quality assessment of the MIPAS data set of monodeuterated water vapour has revealed favourable results. Above $20 \mathrm{~km}$ the MIPAS and ACE-FTS data sets agree quantitatively within $10 \%$, while both instruments exhibit significantly higher VMRs than SMR. This bias can mostly be explained by uncertainties in spectroscopic parameters. Still the latitudinal structures for different seasons exhibit a high degree of consistency among all data sets, making this bias less an issue. Also the vertical structures of the tropical "tape recorder" signal observed by all instruments exhibit good agreement. Above $40 \mathrm{~km}$, where the MIPAS HDO retrieval reaches its limits, still good agreement with the structures observed by SMR is found for most seasons. The largest deviations between the data sets can be found below $20 \mathrm{~km}$, for some latitude bins the relative deviation between MIPAS and ACE-FTS exceeds $100 \%$ below $15 \mathrm{~km}$. Still the latitudinal structures observed by both instruments fit at these altitudes. Higher up, between $15 \mathrm{~km}$ and $20 \mathrm{~km}$, there is less consistency between the data sets. Deviations are found in the Antarctic during winter and spring, as well as in the tropics.

Acknowledgements. This work has been funded by the German Federal Ministry of Education and Research (BMBF) via contract no. 50 EE 0901. J. Steinwagner and T. Röckmann were financially supported by the Dutch Science foundation NWO (grant number ALW-GO-AO/07-01). We would like to thank the European Space Agency (ESA) for making the MIPAS level-1b data set available. Odin is a Swedish-led satellite project funded jointly by the Swedish National Space Board (SNSB), the Canadian Space Agency (CSA), the National Technology Agency of Finland (Tekes) and the Centre National d'Etudes Spatiales (CNES) in France. The Swedish Space Corporation has been the industrial prime constructor. Since April 2007 Odin is a third-party mission of ESA. The Atmospheric Chemistry Experiment (ACE), also known as SCISAT, is a Canadian-led mission mainly supported by the Canadian Space Agency (CSA) and the Natural Sciences and Engineering Research Council of Canada (NSERC). The MIPAS retrievals were partly performed on the HP XC4000 of the KIT Steinbuch Centre for Computing (SCC) under the project grant MIPAS. We acknowledge support by Deutsche Forschungsgemeinschaft (DFG) and the Open Access Publishing Fund of the Karlsruhe Institute of Technology. The main author thanks C. Martin, J. Buckland, G. Berryman and W. Champion for their support.

Edited by: D. Feist

\section{References}

Abbas, M. M., Guo, J., Carli, B., Mencaraglia, F., and Bonetti, A.: Stratospheric $\mathrm{O}_{3}, \mathrm{H}_{2} \mathrm{O}$, and $\mathrm{HDO}$ distributions from balloonbased far-infrared observations, J. Geophys. Res., 92, 83548364, doi:10.1029/JD092iD07p08354, 1987.

Beer, R., Glavich, T. A., and Rider, D. M.: Tropospheric emission spectrometer for the Earth Observing System's Aura satellite, Appl. Optics, 40, 2356-2367, doi:10.1364/AO.40.002356, 2001.

Bernath, P. F., McElroy, C. T., Abrams, M. C., Boone, C. D., Butler, M., Camy-Peyret, C., Carleer, M., Clerbaux, C., Coheur, P.-F., Colin, R., DeCola, P., DeMazière, M., Drummond, J. R., Dufour, D., Evans, W. F. J., Fast, H., Fussen, D., Gilbert, K., Jennings, D. E., Llewellyn, E. J., Lowe, R. P., Mahieu, E., McConnell, J. C., McHugh, M., McLeod, S. D., Michaud, R., Midwinter, C., Nassar, R., Nichitiu, F., Nowlan, C., Rinsland, C. P., Rochon, Y. J., Rowlands, N., Semeniuk, K., Simon, P., Skelton, 
R., Sloan, J. J., Soucy, M.-A., Strong, K., Tremblay, P., Turnbull, D., Walker, K. A., Walkty, I., Wardle, D. A., Wehrle, V., Zander, R., and Zou, J.: Atmospheric Chemistry Experiment (ACE): Mission overview, Geophys. Res. Lett., 32, L15S01, doi:10.1029/2005GL022386, 2005.

Bovensmann, H., Burrows, J. P., Buchwitz, M., Frerick, J., Noël, S., Rozanov, V. V., Chance, K. V., and Goede, A. P. H.: SCIAMACHY: Mission objectives and measurement modes, J. Atmos. Sci., 56, 127-150, doi:10.1175/15200469(1999)056<0127:SMOAMM > 2.0.CO;2, 1999.

Brasseur, G. and Solomon, S.: Aeronomy of the middle atmosphere, ISBN-10 1-4020-3284-6, Springer, Dordrecht, The Netherlands, 2005.

Carlotti, M.: Global-fit approach to the analysis of limb-scanning atmospheric measurements, Appl. Optics, 27, 3250-3254, 1988.

Clerbaux, C., Hadji-Lazaro, J., Turquety, S., George, M., Coheur, P. F., Hurtmans, D., Wespes, C., Herbin, H., Blumstein, D., Tournier, B., and Phulpin, T.: The IASI/MetOp mission: first ob-servations and highlight of its potential contribution to the GMES Earth observation component, Space Res. Today, 168, 19-24, 2007.

Coffey, M. T., Hannigan, J. W., and Goldman, A.: Observations of upper tropospheric/lower stratospheric water vapor and its isotopes, J. Geophys. Res., 111, D14313, doi:10.1029/2005JD006093, 2006.

Connor, B. J., Siskind, D. E., Tsou, J. J., Parrish, A., and Remsberg, E. E.: Ground-based microwave observations of ozone in the upper stratosphere and mesosphere, J. Geophys. Res., 99, 1675716770, doi:10.1029/94JD01153, 1994.

Dinelli, B. M., Carli, B., and Carlotti, M.: Measurement of stratospheric distributions of $\mathrm{H}_{2}^{16} \mathrm{O}, \mathrm{H}_{2}^{18} \mathrm{O}, \mathrm{H}_{2}^{17} \mathrm{O}$, and $\mathrm{HD}^{16} \mathrm{O}$ from far infrared spectra, J. Geophys. Res., 96, 7509-7514, doi:10.1029/90JD02665, 1991.

Dupuy, E., Walker, K. A., Kar, J., Boone, C. D., McElroy, C. T., Bernath, P. F., Drummond, J. R., Skelton, R., McLeod, S. D., Hughes, R. C., Nowlan, C. R., Dufour, D. G., Zou, J., Nichitiu, F., Strong, K., Baron, P., Bevilacqua, R. M., Blumenstock, T., Bodeker, G. E., Borsdorff, T., Bourassa, A. E., Bovensmann, H., Boyd, I. S., Bracher, A., Brogniez, C., Burrows, J. P., Catoire, V., Ceccherini, S., Chabrillat, S., Christensen, T., Coffey, M. T., Cortesi, U., Davies, J., De Clercq, C., Degenstein, D. A., De Mazière, M., Demoulin, P., Dodion, J., Firanski, B., Fischer, H., Forbes, G., Froidevaux, L., Fussen, D., Gerard, P., Godin-Beekmann, S., Goutail, F., Granville, J., Griffith, D., Haley, C. S., Hannigan, J. W., Höpfner, M., Jin, J. J., Jones, A., Jones, N. B., Jucks, K., Kagawa, A., Kasai, Y., Kerzenmacher, T. E., Kleinböhl, A., Klekociuk, A. R., Kramer, I., Küllmann, H., Kuttippurath, J., Kyrölä, E., Lambert, J.-C., Livesey, N. J., Llewellyn, E. J., Lloyd, N. D., Mahieu, E., Manney, G. L., Marshall, B. T., McConnell, J. C., McCormick, M. P., McDermid, I. S., McHugh, M., McLinden, C. A., Mellqvist, J., Mizutani, K., Murayama, Y., Murtagh, D. P., Oelhaf, H., Parrish, A., Petelina, S. V., Piccolo, C., Pommereau, J.-P., Randall, C. E., Robert, C., Roth, C., Schneider, M., Senten, C., Steck, T., Strandberg, A., Strawbridge, K. B., Sussmann, R., Swart, D. P. J., Tarasick, D. W., Taylor, J. R., Tétard, C., Thomason, L. W., Thompson, A. M., Tully, M. B., Urban, J., Vanhellemont, F., Vigouroux, C., von Clarmann, T., von der Gathen, P., von Savigny, C., Waters, J. W., Witte, J. C., Wolff, M., and Zawodny, J. M.: Validation of ozone measurements from the Atmospheric Chemistry Experiment (ACE), Atmos. Chem. Phys., 9, 287-343, doi:10.5194/acp9-287-2009, 2009.

Eriksson, P.: Microwave radiometric observations of the middle atmosphere: Simulations and inversions, Ph.D. thesis, Chalmers University of Technology, School of Electrical and Computational Engineering, Göteburg, Sweden, 1999.

Eriksson, P., Jiménez, C., and Buehler, S. A.: Qpack, a general tool for instrument simulation and retrieval work, J. Quant. Spectrosc. Ra., 91, 47-64, doi:10.1016/j.jqsrt.2004.05.050, 2005.

Farmer, C. B.: High resolution infrared spectroscopy of the sun and the earth's atmosphere from space, Mikrochim. Acta, 3, 189214, 1987.

Fischer, H., Birk, M., Blom, C., Carli, B., Carlotti, M., von Clarmann, T., Delbouille, L., Dudhia, A., Ehhalt, D., Endemann, M., Flaud, J. M., Gessner, R., Kleinert, A., Koopman, R., Langen, J., López-Puertas, M., Mosner, P., Nett, H., Oelhaf, H., Perron, G., Remedios, J., Ridolfi, M., Stiller, G., and Zander, R.: MIPAS: an instrument for atmospheric and climate research, Atmos. Chem. Phys., 8, 2151-2188, doi:10.5194/acp-8-2151-2008, 2008.

Flaud, J. M., Piccolo, C., Carli, B., Perrin, A., Coudert, L. H., Teffo, J. L., and Brown, L. R.: Molecular line parameters for the MIPAS (Michelson Interferometer for Passive Atmospheric Sounding) experiment, Atmos. Ocean. Optics, 16, 172-182, 2003.

Forster, P. M. D. F. and Shine, K. P.: Stratospheric water vapor changes as a possible contributor to observed stratospheric cooling, Geophys. Res. Lett., 26, 3309-3312, doi:10.1029/1999GL010487, 1999.

Frankenberg, C., Yoshimura, K., Warneke, T., Aben, I., Butz, A., Deutscher, N., Griffith, D., Hase, F., Notholt, J., Schneider, M., Schrijver, H., and Röckmann, T.: Dynamic processes governing lower-tropospheric $\mathrm{HDO} / \mathrm{H}_{2} \mathrm{O}$ ratios as observed from space and ground, Science, 325, 1374-1377, doi:10.1126/science.1173791, 2009.

Frisk, U., Hagström, M., Ala-Laurinaho, J., Andersson, S., Berges, J.-C., Chabaud, J.-P., Dahlgren, M., Emrich, A., Florén, H.-G., Florin, G., Fredrixon, M., Gaier, T., Haas, R., Hirvonen, T., Hjalmarsson, Å., Jakobsson, B., Jukkala, P., Kildal, P. S., Kollberg, E., Lassing, J., Lecacheux, A., Lehikoinen, P., Lehto, A., Mallat, J., Marty, C., Michet, D., Narbonne, J., Nexon, M., Olberg, M., Olofsson, A. O. H., Olofsson, G., Origné, A., Petersson, M., Piironen, P., Pons, R., Pouliquen, D., Ristorcelli, I., Rosolen, C., Rouaix, G., Räisänen, A. V., Serra, G., Sjöberg, F., Stenmark, L., Torchinsky, S., Tuovinen, J., Ullberg, C., Vinterhav, E., Wadefalk, N., Zirath, H., Zimmermann, P., and Zimmermann, R.: The Odin satellite, I. Radiometer design and test, Atron. Astrophys. 402, L27-L34, doi:10.1051/0004-6361:20030335, 2003.

Gettelman, A. and Webster, C. R.: Simulations of water isotope abundances in the upper troposphere and lower stratosphere and implications for stratosphere troposphere exchange, J. Geophys. Res., 110, D17301, doi:10.1029/2004JD004812, 2005.

Hagemann, R., Nief, G., and Roth, E.: Absolute isotopic scale for deuterium analysis natural waters, Absolute $D / H$ ratio for SMOW, Tellus, 22, 712-715, 1970.

Hanisco, T. F., Moyer, E. J., Weinstock, E. M., St. Clair, J. M., Sayres, D. S., Smith, J. B., Lockwood, R., Anderson, J. G., Dessler, A. E., Keutsch, F. N., Spackman, J. R., Read, W. G., and Bui, T. P.: Observations of deep convective influence on stratospheric water vapor and its isotopic composition, Geophys. 
Res. Lett., 34, L04814, doi:10.1029/2006GL027899, 2007.

Herbin, H., Hurtmans, D., Clerbaux, C., Clarisse, L., and Coheur, P.-F.: $\mathrm{H}_{2}^{16} \mathrm{O}$ and HDO measurements with IASI/MetOp, Atmos. Chem. Phys., 9, 9433-9447, doi:10.5194/acp-9-9433-2009, 2009.

Holton, J. R., Haynes, P. H., McIntyre, M. E., Douglass, A. R., Rood, R. B., and Pfister, L.: Stratosphere-troposphere exchange, Rev. Geophys., 33, 403-439, doi:10.1029/95RG02097, 1995.

Hurst, D. F., Oltmans, S. J., Vö mel, H., Rosenlof, K. H., Davis, S. M., Ray, E. A., Hall, E. G., and Jordan, A. F.: Stratospheric water vapor trends over Boulder, Colorado: Analysis of the 30 year Boulder record, J. Geophys. Res., 116, D02306, doi:10.1029/2010JD015065, 2011.

Irion, F. W., Moyer, E. J., Gunson, M. R., Rinsland, C. P., Yung, Y. L., Michelsen, H. A., Salawitch, R. J., Chang, A. Y., Newchurch, M. J., Abbas, M. M., Abrams, M. C., and Zander, R.: Stratospheric observations of $\mathrm{CH}_{3} \mathrm{D}$ and HDO from ATMOS infrared solar spectra: Enrichments of deuterium in methane and implications for HD, Geophys. Res. Lett., 23, 2381-2384, doi:10.1029/96GL01402, 1996.

Jacquinet-Husson, N., Arie, E., Ballard, J., Barbe, A., Bjoraker, G., Bonnet, B., Brown, L. R., Camy-Peyret, C., Champion, J. P., Chedin, A., Chursin, A., Clerbaux, C., Duxbury, G., Flaud, J.M., Fourrie, N., Fayt, A., Graner, G., Gamache, R., Goldman, A., Golovko, V., Guelachvili, G., Hartmann, J. M., Hilico, J. C., Hillman, J., Lefevre, G., Lellouch, E., Mikhailenko, S. N., Naumenko, O. V., Nemtchinov, V., Newnham, D. A., Nikitin, A., Orphal, J., Perrin, A., Reuter, D. C., Rinsland, C. P., Rosenmann, L., Rothman, L. S., Scott, N. A., Selby, J., Sinitsa, L. N., Sirota, J. M., Smith, A. M., Smith, K. M., Tyuterev, V. G., Tipping, R. H., Urban, S., Varanasi, P., and Weber, M.: The 1997 spectroscopic GEISA databank, J. Quant. Spectrosc. Rad,, 62, 205-254, doi:10.1016/S0022-4073(98)00111-3, 1999.

Johnson, D. G., Jucks, K. W., Traub, W. A., and Chance, K. V.: Isotopic composition of stratospheric water vapor: Measurements and photochemistry, J. Geophys. Res., 106, 12211-12218, doi:10.1029/2000JD900763, 2001a.

Johnson, D. G., Jucks, K. W., Traub, W. A., and Chance, K. V.: Isotopic composition of stratospheric water vapor: Implications for transport, J. Geophys. Res., 106, 12219-12226, doi:10.1029/2000JD900764, 2001b.

Kelly, K. K., Tuck, A. F., Murphy, D. M., Proffitt, M. H., Fahey, D. W., Jones, R. L., McKenna, D. S., Loewenstein, M., Podolske, J. R., Strahan, S. E., Ferry, G. V., Chan, K. R., Vedder, J. F., Gregory, G. L., Hypes, W. D., McCormick, M. P., Browell, E. V., and Heidt, L. E.: Dehydration in the lower Antarctic stratosphere during late winter and early spring, 1987, J. Geophys. Res., 94, 11317-11357, doi:10.1029/JD094iD09p11317, 1989.

Kley, D., Russell, J. M., and Philips, C.: Stratospheric Processes and their Role in Climate (SPARC) - Assessment of upper tropospheric and stratospheric water vapour, SPARC Report 2, WMO/ICSU/IOC World Climate Research Programme, Geneva, 2000.

Kobayashi, H., Shimota, A., Kondo, K., Okumura, E., Kameda, Y., Shimoda, H., and Ogawa, T.: Development and evaluation of the Interferometric Monitor for Greenhouse Gases: a high-throughput Fourier-transform infrared radiometer for nadir Earth observation, Appl. Optics, 38, 6801-6807, doi:10.1364/AO.38.006801, 1999.
Kuang, Z., Toon, G. C., Wennberg, P. O., and Yung, Y. L.: Measured $\mathrm{HDO} / \mathrm{H}_{2} \mathrm{O}$ ratios across the tropical tropopause, Geophys. Res. Lett., 30, 1372, doi:10.1029/2003GL017023, 2003.

Mote, P. W., Rosenlof, K. H., McIntyre, M. E., Carr, E. S., Gille, J. C., Holton, J. R., Kinnersley, J. S., Pumphrey, H. C., Russell, J. M., and Waters, J. W.: An atmospheric tape recorder: The imprint of tropical tropopause temperatures on stratospheric water vapor, J. Geophys. Res., 101, 3989-4006, doi:10.1029/95JD03422, 1996.

Moyer, E. J., Irion, F. W., Yung, Y. L., and Gunson, M. R.: ATMOS stratospheric deuterated water and implications for tropospherestratosphere transport, Geophys. Res. Lett., 23, 2385-2388, doi:10.1029/96GL01489, 1996.

Murtagh, D. P., Frisk, U., Merino, F., Ridal, M., Jonsson, A., Stegman, J., Witt, G., Eriksson, P., Jiménez, C., Megie, G., de La Noë, J., Ricaud, P., Baron, P., Pardo, J. R., Hauchcorne, A., Llewellyn, E. J., Degenstein, D. A., Gattinger, R. L., Lloyd, N. D., Evans, W. F. J., McDade, I. C., Haley, C. S., Sioris, C., von Savigny, C., Solheim, B. H., McConnell, J. C., Strong, K., Richardson, E. H., Leppelmeier, G. W., Kyrölä, E., Auvinen, H., and Oikarinen, L.: An overview of the Odin atmospheric mission, Can. J. Phys., 80, 309-319, doi:10.1139/p01-157, 2002.

Nassar, R., Bernath, P. F., Boone, C. D., Gettelman, A., McLeod, S. D., and Rinsland, C. P.: Variability in $\mathrm{HDO} / \mathrm{H}_{2} \mathrm{O}$ abundance ratios in the tropical tropopause layer, J. Geophys. Res., 112, D21305, doi:10.1029/2007JD008417, 2007.

Notholt, J., Toon, G. C., Fueglistaler, S., Wennberg, P. O., Irion, F. W., McCarthy, M., Scharringhausen, M., Siek Rhee, T., Kleinböhl, A., and Velazco, V.: Trend in ice moistening the stratosphere - constraints from isotope data of water and methane, Atmos. Chem. Phys., 10, 201-207, doi:10.5194/acp10-201-2010, 2010.

Oltmans, S. J., Vömel, H., Hofmann, D. J., Rosenlof, K. H., and Kley, D.: The increase in stratospheric water vapor from balloonborne, frostpoint hygrometer measurements at Washington, D.C., and Boulder, Colorado, Geophys. Res. Lett., 27, 34533456, doi:10.1029/2000GL012133, 2000.

Payne, V. H., Noone, D., Dudhia, A., Piccolo, C., and Grainger, R. G.: Global satellite measurements of $\mathrm{HDO}$ and implications for understanding the transport of water vapour into the stratosphere, Q. J. Roy. Meteorol. Soc., 133, 1459-1471, doi:10.1002/qj.127, 2007.

Pickett, H. M., Poynter, R. L., Cohen, E. A., Delitsky, M. L., Pearson, J. C., and Müller, H. S. P.: Submillimeter, millimeter and microwave spectral line catalog, J. Quant. Spectrosc. Ra., 60, 883-890, doi:10.1016/S0022-4073(98)00091-0, 1998.

Pollock, W., Heidt, L. E., Lueb, R., and Ehhalt, D. H.: Measurement of stratospheric water vapor by cryogenic collection, J. Geophys. Res., 85, 5555-5568, doi:10.1029/JC085iC10p05555, 1980.

Randall, C. E., Rusch, D. W., Bevilacqua, R. M., Hoppel, K. W., Lumpe, J. D., Shettle, E., Thompson, E., Deaver, L., Zawodny, J., Kyrö, E., Johnson, B., Kelder, H., Dorokhov, V. M., KönigLanglo, G., and Gil, M.: Validation of POAM III ozone: Comparisons with ozonesonde and satellite data, J. Geophys. Res., 108, 4367, doi:10.1029/2002JD002944, 2003.

Randel, W. J., Wu, F., Russell, J. M., Roche, A., and Waters, J. W.: Seasonal cycles and QBO variations in stratospheric $\mathrm{CH}_{4}$ and $\mathrm{H}_{2} \mathrm{O}$ observed in UARS HALOE data, J. Atmos. Sci., 55, 163-185, doi:10.1175/1520- 
0469(1998)055<0163:SCAQVI > 2.0.CO;2, 1998.

Ridal, M.: Water vapour isotopes in the stratosphere, Ph.D. thesis, Stockholm University, Sweden, 2001.

Rinsland, C. P., Smith, M. A. H., Seals Jr., R. K., Goldman, A., Murcray, F. J., Murcray, D. G., Malathy Devi, V., Fridovich, B., Snyder, D. G. S., and Jones, G. D.: Simultaneous stratospheric measurements of $\mathrm{H}_{2} \mathrm{O}, \mathrm{HDO}$, and $\mathrm{CH}_{4}$ from balloon-borne and aircraft infrared solar absorption spectra and tunable diode laser laboratory spectra of HDO, J. Geophys. Res., 89, 7259-7266, doi:10.1029/JD089iD05p07259, 1984.

Rinsland, C. P., Gunson, M. R., Foster, J. C., Toth, R. A., and Farmer, C. B.: Stratospheric profiles of heavy water vapor isotopes and $\mathrm{CH}_{3} \mathrm{D}$ from analysis of the ATMOS Spacelab 3 infrared solar spectra, J. Geophys. Res., 96, 1057-1068, doi:10.1029/90JD02234, 1991.

Risi, C., Bony, S., and Vimeux, F.: Influence of convective processes on the isotopic composition $\left(\delta^{18} \mathrm{O}\right.$ and $\left.\delta \mathrm{D}\right)$ of precipitation and water vapor in the tropics: 2. Physical interpretation of the amount effect, J. Geophys. Res., 113, D19306, doi:10.1029/2008JD009943, 2008.

Rodgers, C. D.: Inverse methods for atmospheric soundings: Theory and practice, ISBN 981-02-2740-X, World Scientific Publishing Co. Pte. Ltd., 2000.

Rosenlof, K. H., Chiou, E.-W., Chu, W. P., Johnson, D. G., Kelly, K. K., Michelsen, H. A., Nedoluha, G. E., Remsberg, E. E., Toon, G. C., and McCormick, M. P.: Stratospheric water vapor increases over the past half-century, Geophy. Res. Lett., 28, 1195-1198, doi:10.1029/2000GL012502, 2001.

Rothman, L. S., Barbe, A., Benner, D. C., Brown, L. R., CamyPeyret, C., Carleer, M. R., Chance, K., Clerbaux, C., Dana, V., Devi, V. M., Fayt, A., Flaud, J.-M., Gamache, R. R., Goldman, A., Jacquemart, D., Jucks, K. W., Lafferty, W. J., Mandin, J.-Y., Massie, S. T., Nemtchinov, V., Newnham, D. A., Perrin, A., Rinsland, C. P., Schroeder, J., Smith, K. M., Smith, M. A. H., Tang, K., Toth, R. A., Vander Auwera, J., Varanasi, P., and Yoshino, K.: The HITRAN molecular spectroscopic database: edition of 2000 including updates through 2001, J. Quant. Spectrosc. Ra., 82, 5-44, doi:10.1016/S0022-4073(03)00146-8, 2003.

Rothman, L. S., Jacquemart, D., Barbe, A., Chris Benner, D., Birk, M., Brown, L. R., Carleer, M. R., Chackerian, C., Chance, K., Coudert, L. H., Dana, V., Devi, V. M., Flaud, J.-M., Gamache, R. R., Goldman, A., Hartmann, J.-M., Jucks, K. W., Maki, A. G., Mandin, J.-Y., Massie, S. T., Orphal, J., Perrin, A., Rinsland, C. P., Smith, M. A. H., Tennyson, J., Tolchenov, R. N., Toth, R. A., Vander Auwera, J., Varanasi, P., and Wagner, G.: The HITRAN 2004 molecular spectroscopic database, J. Quant. Spectrosc. Ra., 96, 139-204, doi:10.1016/j.jqsrt.2004.10.008, 2005.

Sayres, D. S., Pfister, L., Hanisco, T. F., Moyer, E. J., Smith, J. B., St. Clair, J. M., O’Brien, A. S., Witinski, M. F., Legg, M., and Anderson, J. G.: Influence of convection on the water isotopic composition of the tropical tropopause layer and tropical stratosphere, J. Geophys. Res., 115, D00J20, doi:10.1029/2009JD013100, 2010.

Scherer, M., Vömel, H., Fueglistaler, S., Oltmans, S. J., and Staehelin, J.: Trends and variability of midlatitude stratospheric water vapour deduced from the re-evaluated Boulder balloon series and HALOE, Atmos. Chem. Phys., 8, 1391-1402, doi:10.5194/acp8-1391-2008, 2008.
Schmidt, G. A., Hoffmann, G., Shindell, D. T., and $\mathrm{Hu}$ Y.: Modeling atmospheric stable water isotopes and the potential for constraining cloud processes and stratospheretroposphere water exchange, J. Geophys. Res., 110, D21314, doi:10.1029/2005JD005790, 2005.

Scholz, T. G., Ehhalt, D. H., Heidt, L. E., and Martell, E. A.: Water Vapor, Molecular Hydrogen, Methane, and Tritium Concentrations near the Stratopause, J. Geophys. Res., 75, 3049-3054, doi:10.1029/JC075i015p03049, 1970.

Seele, C. and Hartogh, P.: Water vapor of the polar middle atmosphere: Annual variation and summer mesosphere conditions as observed by ground-based microwave spectroscopy, Geophys. Res. Lett., 26, 1517-1520, doi:10.1029/1999GL900315, 1999.

Solomon, S., Rosenlof, K. H., Portmann, R. W., Daniel, J. S., Davis, S. M., Sanford, T. J., and Plattner, G.: Contributions of Stratospheric Water Vapor to Decadal Changes in the Rate of Global Warming, Science, 327, 1219-1223, doi:10.1126/science.1182488, 2010.

Spang, R., Remedios, J. J., and Barkley, M. P.: Colour indices for the detection and differentiation of cloud types in infrared limb emission spectra, Adv. Space Res., 33, 1041-1047, doi:10.1016/S0273-1177(03)00585-4, 2004.

Steinwagner, J., Milz, M., von Clarmann, T., Glatthor, N., Grabowski, U., Höpfner, M., Stiller, G. P., and Röckmann, T.: HDO measurements with MIPAS, Atmos. Chem. Phys., 7, 26012615, doi:10.5194/acp-7-2601-2007, 2007.

Steinwagner, J., Fueglistaler, S., Stiller, G. P., von Clarmann, T., Kiefer, M., Borsboom, P., van Delden, A., and Röckmann, T.: Tropical dehydration processes constrained by the seasonality of stratospheric deuterated water, Nat. Geosci., 3, 262-266, doi:10.1038/ngeo822, 2010.

Stiller, G. P.: The Karlsruhe optimized and precise radiative transfer algorithm (KOPRA), Tech. rep., Wissenschaftliche Berichte FZKA 6487, 2000.

Stowasser, M., Oelhaf, H., Wetzel, G., Friedl-Vallon, F., Maucher, G., Seefeldner, M., Trieschmann, O., v. Clarmann, T., and Fischer, $\mathrm{H}$.: Simultaneous measurements of $\mathrm{HDO}, \mathrm{H}_{2} \mathrm{O}$, and $\mathrm{CH}_{4}$ with MIPAS-B: Hydrogen budget and indication of dehydration inside the polar vortex, J. Geophys. Res., 104, 19213-19226, doi:10.1029/1999JD900239, 1999.

Tikhonov, A. N.: On the solution of incorrectly stated problems and method of regularization, Doklady Akademii Nauk - Proc. Russ. Acad. Sci., 151, 501-504, 1963a.

Tikhonov, A. N.: On the regularization of incorrectly stated problems, Doklady Akademii Nauk - Proc. Russ. Acad. Sci., 153, 49-52, 1963b.

Tikhonov, A. N. and Arsenin, V. Y.: Solutions of ill-posed problems, ISBN 0470991240, Winston Publishing, New York, 1977.

Urban, J., Lautié, N., Murtagh, D. P., Kasai, Y., Dupuy, E., de La Noë, J., El Amraoui, L., Eriksson, P., Frisk, U., Jiménez, C., Le Flochmoën, E., Olberg, M., and Ricaud, P.: Odin/SMR observations of stratospheric water vapour and its isotopes: Requirements on spectroscopy, in: Proceedings of the International Workshop on critical Evaluation of mm-/submm-Wave spectroscopic Data for atmospheric Observations, Irabaki University, Mito/Japan, 29-30 January 2004.

Urban, J., Lautié, N., Murtagh, D. P., Eriksson, P., Kasai, Y., Lossow, S., Dupuy, E., de La Noë, J., Frisk, U., Olberg, M., Le Flochmoën, E., and Ricaud, P.: Global 
observations of middle atmospheric water vapour by the Odin satellite: An overview, Planet. Space Sci., 55, 1093-1102, doi:10.1016/j.pss.2006.11.021, 2007.

Vömel, H., Oltmans, S. J., Hofmann, D. J., Deshler, T., and Rosen, J. M.: The evolution of the dehydration in the Antarctic stratospheric vortex, J. Geophys. Res., 100, 13919-13926, doi:10.1029/95JD01000, 1995.

von Clarmann, T.: Validation of remotely sensed profiles of atmospheric state variables: strategies and terminology, Atmospheric Chemistry \& Physics, 6, 4311 - 4320, doi:10.5194/acp-6-43112006, 2006.

von Clarmann, T., Glatthor, N., Grabowski, U., Höpfner, M., Kellmann, S., Kiefer, M., Linden, A., Tsidu, G. M., Milz, M., Steck, T., Stiller, G. P., Wang, D. Y., Fischer, H., Funke, B., Gil-López, S., and López-Puertas, M.: Retrieval of temperature and tangent altitude pointing from limb emission spectra recorded from space by the Michelson Interferometer for Passive Atmospheric Sounding (MIPAS), J. Geophys. Res., 108, 4736, doi:10.1029/2003JD003602, 2003.

Webster, C. R. and Heymsfield, A. J.: Water Isotope Ratios $D / H$, ${ }^{18} \mathrm{O} /{ }^{16} \mathrm{O},{ }^{17} \mathrm{O} /{ }^{16} \mathrm{O}$ in and out of clouds map dehydration pathways, Science, 302, 1742-1746, doi:10.1126/science.1089496, 2003.
Worden, J., Noone, D., Bowman, K., Beer, R., Eldering, A., Fisher, B., Gunson, M., Goldman, A., Herman, R., Kulawik, S. S., Lampel, M., Osterman, G., Rinsland, C., Rodgers, C., Sander, S., Shephard, M., Webster, C. R., and Worden, H.: Importance of rain evaporation and continental convection in the tropical water cycle, Nature, 445, 528-532, doi:10.1038/nature05508, 2007.

Wrotny, J. E., Nedoluha, G. E., Boone, C., Stiller, G. P., and McCormack, J. P.: Total hydrogen budget of the equatorial upper stratosphere, J. Geophys. Res., 115, D04302, doi:10.1029/2009JD012135, 2010.

Zahn, A., Barth, V., Pfeilsticker, K., and Platt, U.: Deuterium, $\mathrm{O}^{18}$ and tritium as tracers for water vapour transport in the lower stratosphere and tropopause region, J. Atmos. Chem., 30, 25-47, 1998.

Zahn, A., Franz, P., Bechtel, C., Grooß, J.-U., and Röckmann, T.: Modelling the budget of middle atmospheric water vapour isotopes, Atmos. Chem. Phys., 6, 2073-2090, doi:10.5194/acp-62073-2006, 2006. 